\title{
The Development of Dual Vaccines against Lumpy Skin Disease (LSD) and Bovine Ephemeral Fever (BEF)
}

\author{
Nicola Douglass $1,2, * \mathbb{C}$, Ruzaiq Omar ${ }^{1,2}$, Henry Munyanduki ${ }^{1,2}$, Akiko Suzuki ${ }^{1,2} \mathbb{1}$, Warren de Moor ${ }^{1,2}$, \\ Paidamwoyo Mutowembwa ${ }^{3}{ }^{(D}$, Alri Pretorius ${ }^{3}$, Tshifhiwa Nefefe ${ }^{3}$, Antoinette van Schalkwyk ${ }^{3}$, \\ Pravesh Kara ${ }^{3}$, Livio Heath ${ }^{3}$ and Anna-Lise Williamson ${ }^{1,2} \mathbb{D}$ \\ 1 Division of Medical Virology, Department of Pathology, Faculty of Health Sciences, \\ University of Cape Town, Cape Town 7925, South Africa; omar.ruzaiq@gmail.com (R.O.); \\ Henry.munyanduki@pirbright.ac.uk (H.M.); SZKAKI001@myuct.ac.za (A.S.); \\ warren.demoor@uct.ac.za (W.d.M.); Anna-Lise.Williamson@uct.ac.za (A.-L.W.) \\ 2 Institute of Infectious Disease and Molecular Medicine, University of Cape Town, \\ Cape Town 7925, South Africa \\ 3 Onderstepoort Veterinary Institute, ARC, Pretoria 0110, South Africa; mutowembwap@arc.agric.za (P.M.); \\ PretoriusAL@arc.agric.za (A.P.); nefefet@arc.agric.za (T.N.); VanSchalkwykA1@arc.agric.za (A.v.S.); \\ KaraP@arc.agric.za (P.K.); HeathL@arc.agric.za (L.H.) \\ * Correspondence: Niki.Douglass@uct.ac.za; Tel.: +27-832-310-553
}

\section{check for} updates

Citation: Douglass, N.; Omar, R.; Munyanduki, H.; Suzuki, A.; de Moor, W.; Mutowembwa, P.; Pretorius, A.; Nefefe, T.; Schalkwyk, A.v.; Kara, P.; et al. The Development of Dual Vaccines against Lumpy Skin Disease (LSD) and Bovine Ephemeral Fever (BEF). Vaccines 2021, 9, 1215. https://doi.org/10.3390/vaccines 9111215

Academic Editor: Eeva Tuppurainen

Received: 6 September 2021

Accepted: 14 October 2021

Published: 20 October 2021

Publisher's Note: MDPI stays neutral with regard to jurisdictional claims in published maps and institutional affiliations.

Copyright: (C) 2021 by the authors Licensee MDPI, Basel, Switzerland. This article is an open access article distributed under the terms and conditions of the Creative Commons Attribution (CC BY) license (https:// creativecommons.org/licenses/by/ $4.0 /)$.
Abstract: Dual vaccines $(n=6)$ against both lumpy skin disease (LSD) and bovine ephemeral fever (BEF) were constructed, based on the BEFV glycoprotein $(G)$ gene, with or without the BEFV matrix (M) protein gene, inserted into one of two different LSDV backbones, nLSDV $\triangle$ SOD-UCT or nLSDVSODis-UCT. The inserted gene cassettes were confirmed by PCR; and BEFV protein was shown to be expressed by immunofluorescence. The candidate dual vaccines were initially tested in a rabbit model; neutralization assays using the South African BEFV vaccine (B-Phemeral) strain showed an African consensus $G$ protein gene $(\mathrm{Gb})$ to give superior neutralization compared to the Australian (Ga) gene. The two LSDV backbones expressing both Gb and M BEFV genes were tested in cattle and shown to elicit neutralizing responses to LSDV as well as BEFV after two inoculations 4 weeks apart. The vaccines were safe in cattle and all vaccinated animals were protected against virulent LSDV challenge, unlike a group of control naïve animals, which developed clinical LSD. Both neutralizing and T cell responses to LSDV were stimulated upon challenge. After two inoculations, all vaccinated animals produced BEFV neutralizing antibodies $\geq 1 / 20$, which is considered protective for BEF.

Keywords: lumpy skin disease virus; bovine ephemeral fever virus; dual vaccine; neutralization; LSDV challenge

\section{Introduction}

Lumpy skin disease (LSD) and bovine ephemeral fever (BEF) are two cattle diseases of economic importance with low mortality but high morbidity rates [1-3]. LSD is classified as a notifiable disease by the World Organization for Animal Health (OIE); it is characterized by fever, clinical lesions which affect animal hides, reduced milk yields and abortion in pregnant ewes [2,4]. It was initially confined to Africa, but spread to Egypt in 1988, Israel in 1989, followed by the Middle East in the 1990s [5]. More recently, it has spread to Europe and Asia $[3,4,6,7]$

BEF is caused by an RNA virus, belonging to the family Rhabdoviridae, genus Ephemerovirus, group Lyssavirus. Clinically, it presents as a transient disease of 3-4 days, causing sudden fever, salivation, nasal discharge, stiffness and can cause reduced milk production as well as abortion in pregnant ewes and infertility in bulls [1,8]. The disease is endemic in Africa, the Middle East, Asia and Australia [9-11]. A live attenuated vaccine, B-phemeral 
is commercially available as a two-dose vaccine regimen, supplied by Onderstepoort Biological Products (OBP) [12].

Geographically, BEF and LSD show considerable overlap, notably in Africa (Figure 1). Both diseases are seasonal, with the causative viruses being spread by biting insects. Ideally, vector control could reduce the incidence of both viral infections, but the implementation of this intervention is impractical. Effective vaccines are available for LSD and BEF, but, due to the seasonal nature of the diseases, are not always considered necessary by animal owners. The development of a single vaccine for control of the two viral diseases would be attractive to both cattle owners as well as vaccine manufactures, due to the reduction in cost and number of vaccines administered. In addition, concomitant vaccination against the two diseases will automatically reduce the incidence of BEF, which is largely under-reported, despite being of great economic importance.

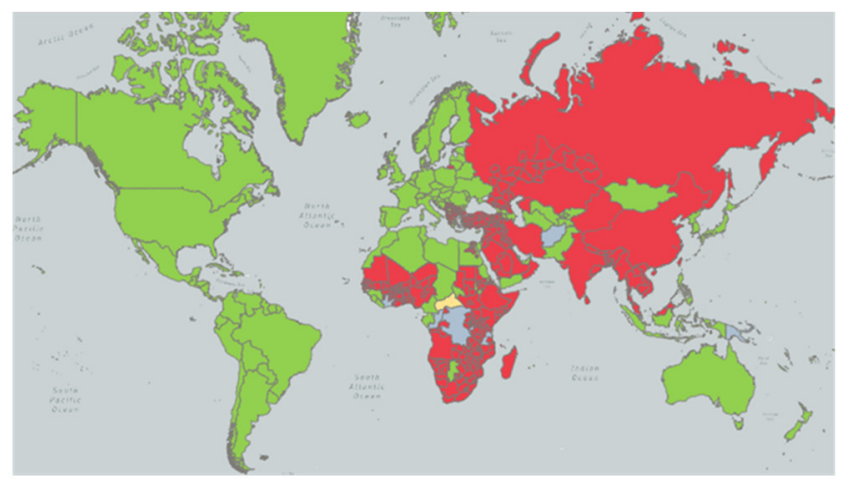

OIE-WAHIS: World Organization for Animal Health. Lumpy skin disease (2017-2021). https://wahis.oie.int/\#/dashboards/country-or-diseasedashboard (accessed 17/08/2021)

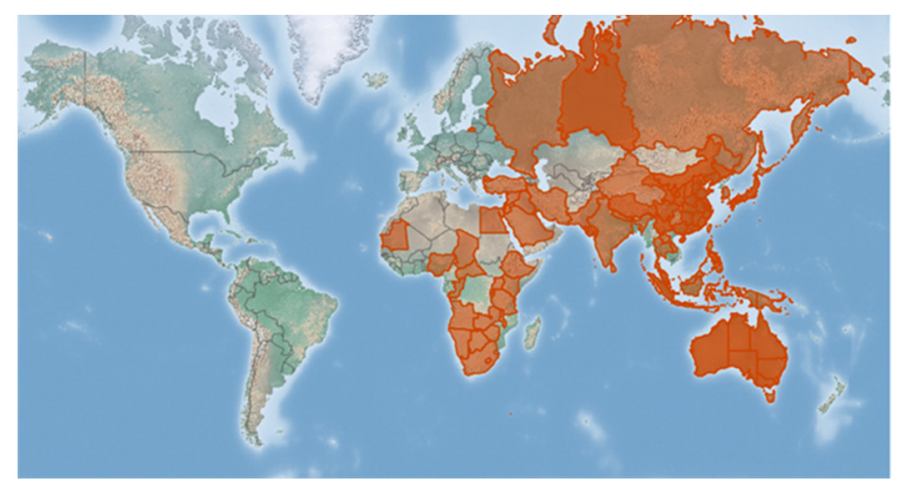

CABI, 2021. bovine ephemeral fever. In: Invasive Species Compendium. Wallingford, UK: CAB International. https://www/cabi.org/isc (accessed $17 / 08 / 2021$ )

Figure 1. Geographical distribution of LSDV and BEFV. LSDV information was obtained from the OIE-WAHIS World Organization for Animal Health. LSD disease status is represented as: red-present, yellow—suspected, green-absent, grey-no information available. BEFV information was obtained from CABI.

Bovine ephemeral fever virus (BEFV) has a single serotype worldwide and, although the presently available vaccines protect against all strains, it is known that neutralising antibodies appear higher against homologous strains [11]. The BEFV glycoprotein (G) has been shown to be immunogenic both as a protein [13] and recombinant vaccinia virus vaccine [14]. The protein has been well characterized immunologically and four neutralizing epitopes have been identified [15-17]. In this study, separate candidate vaccines were made, based either on the Walker $\mathrm{G}$ protein sequence, referred to as $\mathrm{Ga}$, or a consensus South African G protein sequence, referred to as Gb, derived from published South African sequences [18]. In addition, two vaccines were designed to express the matrix (M) protein gene together with Gb. The BEFV matrix protein gene is highly conserved and the Walker and South African M protein sequences are identical [12,19].

Poxviruses have been recognized as excellent vectors for vaccines against human and animal pathogens, eliciting both humoral and cellular protective immune responses [20]. Lumpy skin disease virus (LSDV), a member of the Poxviridae family, genus Capripoxviridae, is both the causative agent of lumpy skin disease (LSD) as well as an attractive vaccine vector for cattle. With the ability to accommodate large insertions, it can be engineered as a mono- or multi-valent vaccine [21-24]. Multiple safe and effective LSDV vaccines are available and five have been compared with respect to virological, clinical and serological properties [25]. In particular, the live attenuated Neethling vaccine strain, made by Onderstepoort Biological Products (OBP), has been shown to be highly effective in protecting cattle against LSD [26,27]. Recently, a killed version of this vaccine has been shown to protect against virulent LSDV challenge [28]. 
Our group has made two variants of the OBP Neethling vaccine strain, nLSDV $\triangle$ SODUCT and nLSDVSODis-UCT; these correspond to superoxide dismutase (SOD) gene homologue knock-out and knock-in mutants, respectively [29]. nLSDVSODis-UCT has a full-length SOD homologue gene which was stabilized by the alteration of nucleotide sequences in a run of AT binucleotides such that the amino acid sequence of the full-length SOD homologue was retained [30]. Both nLSDV $\triangle$ SOD-UCT and nLSDVSODis-UCT were used as vector backbones to express one or two bovine ephemeral fever virus (BEFV) genes, with the aim of generating dual vaccines against LSDV and bovine ephemeral fever virus (BEFV). In total, six candidate LSDV-BEFV vaccines were constructed. These were first tested in a rabbit model for neutralization responses to BEFV and LSDV, and thereafter, two candidate vaccines were selected for testing in cattle, for immunogenicity against LSDV and BEFV; and challenge against virulent LSDV. The aim was to identify a dual vaccine which would induce neutralizing responses to both BEFV and LSDV. In addition, LSDVand BEFV-specific $T$ cell responses would be desirable. The ultimate goal was to obtain protection against virulent LSDV challenge.

\section{Materials and Methods}

2.1. Viruses and Vaccine Preparation

\subsubsection{LSDV}

Modified LSDV Neethling vaccines, nLSDV $\triangle$ SOD-UCT and nLSDVSODis-UCT, were available within our group [29] and used as vector backbones in the construction of dual vaccines against LSDV and BEFV. Candidate vaccines tested in rabbits were grown in Madin Darby bovine kidney (MDBK) cells (CCL-22), obtained from ATCC, and infected at a multiplicity of infections (MOI) of 0.2 for 6 days. Because these cells harbour bovine viral diarrhea virus (BVDV), vaccines used for the cattle experiment were passaged twice through specific pathogen free (SPF) eggs from White Leghorn chickens (AviFarms, South Africa) [31] to remove BVDV, before being grown to higher titres in primary lamb testes cells, which were prepared from foetal lamb testes (LT) obtained through the animal unit at the University of Cape Town, and infected at an MOI of 0.001 for 7 days. Infected cells were freeze/thawed three times and, after a clarifying centrifugation step, the virus was pelleted through a $36 \%$ sucrose cushion, resuspended in phosphate-buffered saline (PBS) (Gibco, Waltham, MA, USA), aliquoted and stored at $-80^{\circ} \mathrm{C}$. Vaccines were titrated in MDBK cells using the TCID 50 method of Reed and Muench [32]. All recombinant vaccines were confirmed to be correct by PCR amplification across the LSDV49-50 loci (Section 2.3), followed by Sanger sequencing of the amplified products (done by the Central Analytical Facility at Stellenbosch University). BEFV gene expression was shown by immunofluorescence (Section 2.4).

\subsubsection{BEFV}

BEFV vaccine B-Phemeral (OBP, Pretoria, South Africa) was used for neutralization assays. The virus was grown in baby hamster kidney (BHK-21) cells (CCL-10), obtained from ATCC, and infected at an MOI of 0.2 for 4-5 days. Concentrated virus was resuspended in PBS, aliquoted and stored at $-80^{\circ} \mathrm{C}$. The virus was titrated in BHK-21 cells using the $\mathrm{TCID}_{50}$ method of Reed and Muench [32].

\subsection{Construction of Recombinant LSDV-BEFV Vaccine Candidates}

The components of the different vaccines made are described in Section 2.2.1 and have been summarized in Table 1. 
Table 1. Summary of components used in the construction of six different LSDV-BEFV dual vaccines.

\begin{tabular}{|c|c|c|c|}
\hline Vaccine & LSDV Parent Virus & $\begin{array}{l}\text { Genes Inserted between LSDV ORFS } \\
\qquad 49 \text { and } 50 *\end{array}$ & Marker * \\
\hline nLSDV $\Delta$ SOD-UCT & $\begin{array}{l}\text { Neethling LSDV vaccine with SOD } \\
\text { homolog gene (ORF 131) deleted [29] }\end{array}$ & parent virus with no gene insertions & None \\
\hline nLSDVSODis-UCT & $\begin{array}{l}\text { Neethling LSDV vaccine with full } \\
\text { length modified SOD homolog gene } \\
\text { (ORF 131) [29] }\end{array}$ & parent virus with no gene insertions & None \\
\hline $\mathrm{LSDV}(\triangle \mathrm{SOD}) \mathrm{BEFV}-\mathrm{Ga}$ & nLSDV $\triangle$ SOD-UCT & \multirow{2}{*}{$\begin{array}{l}\text { BEFV glycoprotein gene of Australian } \\
\text { origin }(\mathrm{Ga})[14]\end{array}$} & \multirow{2}{*}{ mCherry } \\
\hline LSDV(SODis)BEFV-Ga & nLSDVSODis-UCT & & \\
\hline $\mathrm{LSDV}(\triangle \mathrm{SOD}) \mathrm{BEFV}-\mathrm{Gb}$ & nLSDV $\Delta$ SOD-UCT & \multirow{2}{*}{$\begin{array}{c}\text { BEFV glycoprotein gene based on } \\
\text { consensus sequence of South African G } \\
\text { protein genes }(\mathrm{Gb})[18]\end{array}$} & \multirow[t]{2}{*}{ eGFP } \\
\hline LSDV(SODis)BEFV-Gb & nLSDVSODis-UCT & & \\
\hline LSDV( $\triangle \mathrm{SOD}) \mathrm{BEFV}-\mathrm{Gb}-\mathrm{M}$ & nLSDV $\triangle$ SOD-UCT & \multirow{2}{*}{$\begin{array}{l}\text { BEFV glycoprotein gene based on } \\
\text { consensus sequence of South African G } \\
\text { protein genes (Gb) [18] and matrix gene } \\
\text { (M) [19] }\end{array}$} & \multirow[t]{2}{*}{ eGFP } \\
\hline LSDV(SODis)BEFV-Gb-M & nLSDVSODis-UCT & & \\
\hline
\end{tabular}

\subsubsection{Transfer Vector Design}

Transfer vectors were designed such that the foreign gene cassettes were placed between flanking sequences corresponding to the ends of convergent LSDV open reading frames (ORFs) 49 (positions 1682 to 2031) and 50 (positions 1 to 450) from LSDV sequence AF409138.1 obtained from GenBank [37].

The Australian Walker BEFV G protein gene was obtained from GenBank: M94266.1 [14] and was placed under the control of the modified vaccinia virus promoter (PmH5) (GenBank: FJ386852.1) [33]. The Australian G protein gene (Ga) was inserted together with the mCherry fluorescent marker gene under the control of a fowlpox virus promoter (PmFPV), which was identified as a bidirectional promoter [34], but was modified such that the early promoter was retained and the late promoter removed [38]. The transfer vector pBEFV_Ga_mCherry, containing the elements required for homologous recombination with nLSDV $\triangle$ SOD-UCT and nLSDVSODis-UCT, was used to generate LSDV( $\triangle \mathrm{SOD}) \mathrm{BEFV-Ga}$ and LSDV(SODis)BEFV-Ga, respectively.

The South African BEFV G gene, Gb, was derived from a consensus sequence of 14 BEFV isolates collected between 1968 and 1999 [18] and placed under the control of PmH5 (GenBank: FJ386852.1) [33]. This gene was inserted together with a green fluorescent protein gene, eGFP, under the control of the synthetic vaccinia virus promoter (pS) $[35,36]$ into nLSDV $\triangle$ SOD-UCT and nLSDVSODis-UCT, using transfer vector pBEFV_Gb_eGFP, to generate recombinant viruses LSDV( $\triangle \mathrm{SOD}) \mathrm{BEFV-Gb}$ and LSDV(SODis)BEFV-Gb, respectively.

LSDV( $\triangle$ SOD)BEFV-Gb-M and LSDV(SODis)BEFV-Gb-M were constructed using transfer vector pBEFV_Gb_M_eGFP, which was equivalent to pBEFV_Gb_eGFP, but, in addition, had the matrix protein gene, $\mathrm{M}$, under the control of PmFPV, downstream of the Gb gene.

All the elements described above were commercially synthesized by GenScript (Hong Kong). The amino acid sequences of the genes described were retained; however, nucleotide sequences were modified to remove runs of four or more Cs and Gs, poxvirus transcription termination sites (T5NT) and unwanted restriction enzyme sites. 


\subsubsection{Construction of LSDV( $\triangle \mathrm{SOD}) \mathrm{BEFV}-\mathrm{Ga}, \mathrm{LSDV}(\triangle \mathrm{SOD}) \mathrm{BEFV}-\mathrm{Gb}$ and LSDV $(\triangle \mathrm{SOD})$ BEFV-Gb-M}

The three recombinants, LSDV( $\triangle$ SOD)BEFV-Ga, LSDV $(\triangle S O D) B E F V-G b$ and LSDV ( $\triangle \mathrm{SOD}$ )BEFV-Gb-M, were isolated in the following way: primary foetal lamb testes (LT) cells were infected with the parental virus, nLSDV $\triangle$ SOD-UCT (at MOI of 0.25 for construction of LSDV( $\triangle \mathrm{SOD}) \mathrm{BEFV}-\mathrm{Ga}$ and MOI of 0.01 for the other two recombinants) whilst still in suspension after trypsinization, and plated in 12 -well plates at $5 \times 10^{5}$ cells per well. Twenty-four hours post infection, cells were transfected with transfer vectors pBEFV_Ga_mCherry, pBEFV_Gb_eGFP and pBEFV_Gb_M_eGFP, respectively, using XtremeGene HP (Roche, Basel, Switzerland) according to the manufacturer's instructions. Infected and transfected cells were incubated for a further 2 (for LSDV $(\triangle \mathrm{SOD}) \mathrm{BEFV}-\mathrm{Ga}$ and LSDV $(\triangle S O D) B E F V-G b-M)$ or 3 (for LSDV( $\triangle S O D) B E F V-G b$ ) days. Crude lysates were recovered by freezing and thawing the cells twice and passaged on MDBK cells. Fluorescing foci were picked 3-5 days post infection and suspended in Dulbecco's Modified Eagle Medium (DMEM) GlutaMax with high glucose (Gibco, Waltham, MA, USA). The picked foci were lysed by two rounds of freeze/thawing and the lysate used to infect fresh MDBK cells. This procedure was repeated seven to thirteen times per recombinant, until only fluorescent foci were visible, at which stage the recombinants were confirmed to be correct by PCR. Before high titre stocks were prepared (as described in Section 2.1.1), the recombinant viruses were diluted and passaged in 96-well plates such that, for each recombinant, a single focus in a single well was purified and expanded.

\subsubsection{Construction of LSDV(SODis)BEFV-Ga, LSDV(SODis)BEFV-Gb and LSDV(SODis)BEFV-Gb-M}

Primary LT cells were seeded into 12-well plates $18 \mathrm{~h}$ prior to infection, such that they were approximately $80 \%$ confluent, in a logarithmic phase of growth. Monolayers were infected with nLSDVSODis-UCT, at an MOI of 1 , for $2 \mathrm{~h}$ before being transfected with the appropriate transfer vector (pBEFV_Ga_mCherry for LSDV(SODis)BEFV-Ga, pBEFV_Gb_eGFP for LSDV(SODis)BEFV-Gb and pBEFV_Gb_M_eGFP for LSDV(SODis) BEFV-Gb-M), using X-tremeGene HP (Roche, Basel, Switzerland). Three days post transfection, the cells were freeze/thawed and recombinant fluorescing foci were purified in MDBK cells as described in Section 2.2.2. Using this method, the parental virus was lost earlier, by passage 4 , after which single foci were purified from single wells of 96 -well plates using end-point dilutions.

\subsection{PCR Confirmation of LSDV-BEFV Recombinants}

The insertion of the foreign gene cassette between LSDV ORFs 49 and 50 was confirmed by polymerase chain reaction (PCR) followed by agarose gel electrophoresis and Sanger DNA sequencing of the amplicon. The primer sequences used were $5^{\prime}$-GAGTGAAG CCTGGAACAT-3' (forward) and 5'-ACTCTATCGCATCTGGAAACT-3' (reverse). These generated fragment sizes of $1329 \mathrm{bp}$ for the parent viruses nLSDV $\triangle \mathrm{SOD}-\mathrm{UCT}$ and nLSDVSODis-UCT, $4816 \mathrm{bp}$ for LSDV( $\triangle$ SOD)BEFV-Ga and LSDV(SODis)BEFV-Ga, $4842 \mathrm{bp}$ for LSDV( $\triangle$ SOD)BEFV-Gb and LSDV(SODis)BEFV-Gb and $5574 \mathrm{bp}$ for LSDV( $\triangle \mathrm{SOD})$ BEFVGb-M and LSDV(SODis)BEFV-Gb-M. Phusion High-Fidelity enzyme was used with HF Buffer (New England BioLabs, Ipswich, MA, USA). The following thermocycling parameters were used for all PCR reactions: initial denaturation at $98{ }^{\circ} \mathrm{C}$ for $5 \mathrm{~min}$ followed by 40 cycles of denaturation at $98^{\circ} \mathrm{C}$ for $30 \mathrm{~s}$, annealing at $56^{\circ} \mathrm{C}$ for $30 \mathrm{~s}$, extension at $72{ }^{\circ} \mathrm{C}$ for $6 \mathrm{~min}$ and final extension at $72{ }^{\circ} \mathrm{C}$ for $10 \mathrm{~min}$. PCR products were separated on $0.8 \%$ agarose gels, containing $0.5 \mu \mathrm{g} / \mathrm{mL}$ ethidium-bromide, by electrophoresis in $1 \times \mathrm{TBE}$ buffer.

\subsection{Immunofluorescence}

Rabbit antiserum to B-phemeral virus was obtained from Stellenbosch University. A rabbit was immunized intravenously into the marginal ear vein with nine inoculations of 
B-phemeral virus administered alone (days $0,3,10,17,29,38,55,58,65$ ), followed by nine inoculations of BEFV complexed with naked bacteria, six weeks later (days 0, 4, 7, 15, 18, $22,28,32$ and 35) [39]. The final bleed was taken on day 42 of the second set of inoculations.

Immunofluorescence was used to detect BEFV protein in cells infected with the six recombinants, LSDV( $\triangle S O D) B E F V-G a$, LSDV(SODis)BEFV-Ga, LSDV( $\triangle S O D) B E F V-G b$, LSDV(SODis)BEFV-Gb, LSDV( $\triangle$ SOD)BEFV-Gb-M and LSDV(SODis)BEFV-Gb-M. As controls, cells were infected with nLSDV $\triangle$ SOD-UCT or nLSDVSODis-UCT (negative controls) or B-phemeral (positive control). MDBK cells, seeded in chamber slides, were infected at an MOI of 0.1 for $48 \mathrm{~h}$. The cells were washed and fixed with $4 \%$ paraformaldehyde for $10 \mathrm{~min}$, followed by methanol for $30 \mathrm{~s}$ before being washed twice with PBS for $10 \mathrm{~s}$. The slides were incubated overnight with rabbit serum (diluted 1:1000), which had been pre-adsorbed with the lysed cellular debris of approximately $4 \times 10^{7}$ MDBK cells, which were freeze/thawed and centrifuged at $15,000 \times g$ for $10 \mathrm{~min}$. The rabbit serum was added to the cellular debris in $10 \mathrm{~mL}$ PBS with $2 \%$ BSA and pre-adsorbed for $4 \mathrm{~h}$, after which the cell debris was removed by centrifugation at $3000 \times g$ for $7 \mathrm{~min}$ and the supernatant was used. After incubation with primary antibody the cells were washed twice with PBS and the secondary antibody was added. For detection of BEFV protein from recombinants expressing Ga, cells were treated with donkey anti-rabbit Alexa488 (green) secondary antibody (Sigma) (diluted 1:500); for detection of BEFV expression from recombinants expressing Gb and Gb-M, cells were treated with donkey anti-rabbit CY3 (red) secondary antibody (Sigma) (diluted 1:500). Cells were incubated with secondary antibody for $1.5 \mathrm{~h}$, washed with PBS $(2 \times 10 \mathrm{~min})$ and stained with Hoechst solution $(1 \mathrm{uL}$ Hoechst in $5 \mathrm{~mL}$ PBS) for $1 \mathrm{~min}$. After two washes with PBS (10 min each), the top of the chamber slide was removed and the slide allowed to air dry for $5 \mathrm{~min}$. A drop of mowiol with n-propylgallate (anti-fade) was added and a coverslip placed over the cells. The slides were viewed the following day using an inverted Zeiss LMS 880 with airyscan confocal microscope (Zeiss, Oberkochen, Germany).

\subsection{Rabbit Immunization}

All candidate LSDV-BEFV vaccines were tested in female New Zealand white rabbits of approximately 2 months old, weighing $>2 \mathrm{~kg}$ each, with five animals per group. One rabbit died during the acclimatization period and so the control group (inoculated with nLSDV $\triangle$ SOD-UCT) had only four rabbits. The vaccines were administered intramuscularly (i.m.) as two inoculations of $500 \mathrm{uL}$ into each hind leg. Each animal received three homologous doses of $10^{6} \mathrm{TCID}_{50}$ given at four-week intervals. Two weeks after the final inoculation blood was collected by cardiac puncture. Serum was heat-inactivated at $56{ }^{\circ} \mathrm{C}$ for $45 \mathrm{~min}$.

The rabbit experiments were performed at Stellenbosch University in an insect-free facility and animals were handled by an experienced veterinary surgeon and animal technicians. Approval to perform these experiments was granted by the animal ethics committee at the University of Cape Town, FHS reference number 018_039 and South African Department of Agriculture, Forestry and Fisheries reference number 12/11/1/7/1.

\subsection{Cattle Immunization and Challenge with Virulent LSDV}

The two candidate vaccines LSDV( $\triangle S O D) B E F V-G b-M$ and LSDV(SODis)BEFV-Gb-M were tested in Friesian cattle at the ARC-Onderstepoort Veterinary Research Institute (Transboundary Animal Diseases) facility. Permission was granted to do this experiment by the South African Department of Agriculture, Land Reform and Rural Development (DALRRD), reference number $12 / 11 / 1 / 1$. Two groups $(n=10)$ of cattle $>6$ months of age, shown to be LSDV negative by the serum neutralization test (SNT), were vaccinated subcutaneously with LSDV( $\triangle$ SOD)BEFV-Gb-M and LSDV(SODis)BEFV-Gb-M, respectively, with an initial inoculation (day 0 ) of $10^{5} \mathrm{TCID}_{50}$ per animal followed by a homologous boost of $5 \times 10^{4}$ TCID $_{50}$ on day 32. Serum was prepared from blood samples collected at 
days 0,14 and 28 post vaccination (dpv); and 14, 30 and 169 days post boost (dpb) and inactivated at $60^{\circ} \mathrm{C}$ for $30 \mathrm{~min}$.

On day 201 (169 dpb), cattle were challenged with a total of $1 \times 10^{7}$ TCID $_{50}$ virulent LSDV (LSDV/Cradock-EC/RSA/1958) per animal, administered intradermally at multiple sites (to mimic vector biting) and intravenously in a $2 \mathrm{~mL}$ volume in the neck vein. A control group of three naïve animals, shown to be LSDV seronegative by SNT, were also inoculated in the same way. All animals were monitored for 28 days post challenge and rectal temperatures were recorded. Blood was taken on days $0,7,14,21$ and 28 days post challenge (dpc) for whole blood T cell assays as well as neutralization assays (LSDV and BEFV) and BEFV Enzyme-Linked Immunosorbent Assay (ELISA).

\subsection{LSDV Neutralization}

Serum samples were sent to the Diagnostics Services Programme laboratory of the ARC-Onderstepoort Veterinary Institute for lumpy skin disease serum neutralization (LDVSNT) testing. A neutralization titre greater than or equal to $1 / 4$ was considered positive.

\subsection{BEFV Neutralization}

An in-house BEFV neutralization test was set up at the University of Cape Town to test the ability of serum to neutralize infection of BHK-21 cells with BEFV (B-phemeral vaccine (OBP)). Two-fold serial dilutions were made of sera, starting with $1 / 5$, in DMEM (Gibco, Waltham, MA, USA) supplemented with $1 \%$ penicillin-streptomycin (Gibco, Waltham, MA, USA). BEFV was diluted in $1 \times$ PBS to obtain $50 \mathrm{pfu} / 50 \mu \mathrm{L}$ (rabbit experiments) or $25 \mathrm{pfu} / 50 \mu \mathrm{L}$ (cattle experiment). To each well of a 96-well tissue culture plate, $50 \mu \mathrm{L}$ of each serial dilution of serum and $50 \mu \mathrm{L}$ of the diluted BEFV were added. Each serum dilution was tested in ten replicates for the sera from the vaccinated animals and in eight replicates for the pre-immune sera. Following a 2-h incubation at $37^{\circ} \mathrm{C}$ in a $\mathrm{CO}_{2}$ incubator, $100 \mu \mathrm{L}$ of BHK-21 cells at a concentration of $2 \times 10^{5}$ cells/well were seeded and plates were further incubated at $37^{\circ} \mathrm{C}$ for 4 days. Wells containing BHK-21 cells only and wells with $\mathrm{BEFV}+\mathrm{BHK}-21$ cells were included in each plate as a negative control and virus control, respectively. For the testing of the cattle serum, a rabbit serum sample was selected as an internal positive control. Neutralization titres were determined as the reciprocal of the highest dilution of serum showing inhibition of BEFV infection in $\geq 50 \%$ of BEFV-infected wells [40]. Final SNTs were taken from experiments which showed reproducibility of the positive control. A neutralization titre greater than or equal to $1 / 5$ was considered positive.

\subsection{BEFV Enzyme-Linked Immunosorbent Assay (ELISA)}

The presence of binding antibodies to BEFV was tested using a BEFV antibody ELISA kit (Unibiotest, Wuhan, China). Pre-immune sera and sera from $14 \mathrm{dpb}$ and $30 \mathrm{dpb}$ were diluted 1:10 and added to each well of the 96-well microtiter plates provided, which had been coated with BEFV G protein antigen derived from a truncated Asian sequence. Following 30-min to 1 -h incubation at $37^{\circ} \mathrm{C}$, the plates were washed thrice with $1 \times$ PBS containing $0.1 \%$ Tween 20 (PBS-T), and $100 \mu \mathrm{L}$ of rabbit-anti-bovine IgG antibody conjugated with horseradish peroxidase (HRP) were added to each well. The plates were incubated for $30 \mathrm{~min}$ to $1 \mathrm{~h}$ at $37^{\circ} \mathrm{C}$. After the plates were washed thrice with PBS-T as described previously, $100 \mu \mathrm{L}$ of $3,3^{\prime}, 5,5^{\prime}$-tetramethylbenzidine (TMB) substrate was added to each well, and the plates were incubated in dark for 10 to $15 \mathrm{~min}$ at $37^{\circ} \mathrm{C}$. The enzymatic reaction was terminated by the addition of $100 \mu \mathrm{L}$ stop solution to each well. Absorbance was measured at $450 \mathrm{~nm}\left(\mathrm{OD}_{450}\right)$ using a Versa Max Microplate reader and SoftMax Pro Software version 6.3 (Molecular Devices, San Jose, CA, USA). Positive and negative controls were included in the ELISA kit and each sample was tested in duplicate or triplicate. Sera with $\mathrm{OD}_{450} \leq 0.22$ were regarded as negative and $\mathrm{OD}_{450}>0.30$ as positive. 


\subsection{T Cell Assays}

Samples were collected pre-challenge and 7, 14 and 21 days post challenge (dpc). Whole blood was mixed 1:1 with medium [RPMI (Gibco, Waltham, MA, USA) plus 1\% penicillin-streptomycin (Sigma-Aldrich, St Louis, MO, USA)] referred to as the unstimulated control or with LSDV Neethling strain, BEFV virus or with BHK-21 cells at a 1:10 dilution in medium. Blood was seeded in 96-well plates in triplicate with a total volume of $200 \mu \mathrm{L} /$ well. Blood was incubated for $24 \mathrm{~h}$ in a humidified, $5 \% \mathrm{CO}_{2}$ incubator at $37^{\circ} \mathrm{C}$ and brefeldin A was added during the last $5 \mathrm{~h}$ of incubation. Red blood cells were removed by lysis using BD Pharm Lyse ${ }^{\mathrm{TM}}$ lysing solution (BD Biosciences, Franklin Lakes, NJ, USA), cells were fixed with $4 \%$ paraformaldehyde, perforated $(0.05 \%$ Saponin) and then stained with anti-CD4-FITC (1:50 dilution; BioRad, Hercules, CA, USA); anti-CD8-PE (BioRad, 1:20 dilution) and Mouse anti-Bovine Interferon Gamma:Alexa Fluor ${ }^{\circledR} 647$ (1:100 dilution; BioRad, Hercules, CA, USA). Samples were assayed on a FC 500 Beckman Coulter flow cytometer and data analysed using Kaluza version 2.1 (Beckman Coulter, Brea, CA, USA). Values significantly higher than unstimulated control $(p \leq 0.05)$ were considered positive. The $21 \mathrm{dpc}$ analyses data only included anti-CD8 antibodies and IFN $\gamma$ due to a shortage of anti-CD4 antibody.

\subsection{Statistical Analysis}

Statistical analysis was performed using GraphPad Prism 8 (GraphPad Software, San Diego, CA, USA). A parametric $t$-test or non-parametric Mann-Whitney U test were used for the comparison between two different vaccine groups. Analysis for the unpaired multiple comparison between different time points within a single vaccine group or different vaccine groups at a single time point was performed using Welch one-way analysis of variance (ANOVA) with Dunnett's T3 multiple comparison test or Kruskal-Wallis test with Dunn's multiple comparison test. The paired multiple comparison between different time points within a single vaccine group was performed using repeated measures ANOVA test with Tukey's multiple comparison test. $p$-values less than 0.05 were considered statistically significant.

\subsection{Ethics}

Authorization to grow LSDV in eggs was granted by the University of Cape Town Animal Ethics committee, (018/012). Ethics approval to test the candidate vaccines in rabbits was granted from the University of Cape Town (AEC 018_039), Stellenbosch University (UCT-DOUG-2019) and the South African Department of Agriculture, Forestry and Fisheries (DAFF), ref: 12/11/1/7/1. Ethics approval for the cattle experiment to be performed at the ARC institute-Onderstepoort Veterinary Research (Transboundary Animal Diseases) was granted by the South African Department of Agriculture, Land Reform and Rural Development (DALRRD), study number: TADP-S-20/02, [DALRRD Ref no: $12 / 11 / 1 / 1]$.

\section{Results}

\subsection{Construction and Confirmation of Candidate Vaccines against LSDV and BEFV}

Two variants of the Neethling vaccine strain of LSDV, nLSDV $\triangle$ SOD-UCT and nLSDVSODis-UCT [29], were used as parent viruses in the construction of candidate dual vaccines against LSD and BEF. Figure 2 shows, diagrammatically, the design of the LSDV recombinants, whereby the foreign gene cassette was inserted between LSDV open reading frames (ORFs) 49 and 50, which are highly conserved and transcriptionally convergent [41]. The two recombinants, LSDV( $\triangle S O D$ )BEFV-Ga and LSDV(SODis)BEFV-Ga, were made to express the BEFV $G$ protein gene derived from an Australian BEFV sequence $(\mathrm{Ga})$ together with the red fluorescent protein, mCherry, as a marker. LSDV $(\triangle \mathrm{SOD}) \mathrm{BEFV}-\mathrm{Gb}$ and LSDV(SODis)BEFV-Gb expressed a BEFV G protein gene derived from a consensus South African sequence $(\mathrm{Gb})$ as well as the green fluorescent protein (eGFP) as a marker. LSDV $(\triangle \mathrm{SOD})$ BEFV-Gb-M and LSDV(SODis)BEFV-Gb-M expressed the matrix (M) protein 
together with the South African Gb protein and eGFP. All G protein genes were expressed from the vaccinia virus $\mathrm{mH} 5$ promoter $(\mathrm{PmH} 5)$ and the $\mathrm{M}$ gene was expressed from a modified fowlpoxvirus promoter (PmFPV). The six recombinants were confirmed to be correct by PCR (Figure 3) and Sanger sequencing of the gene cassette inserted between LSDV ORFs 49 and 50. BEFV gene expression was verified by immunofluorescence (Figure 4).

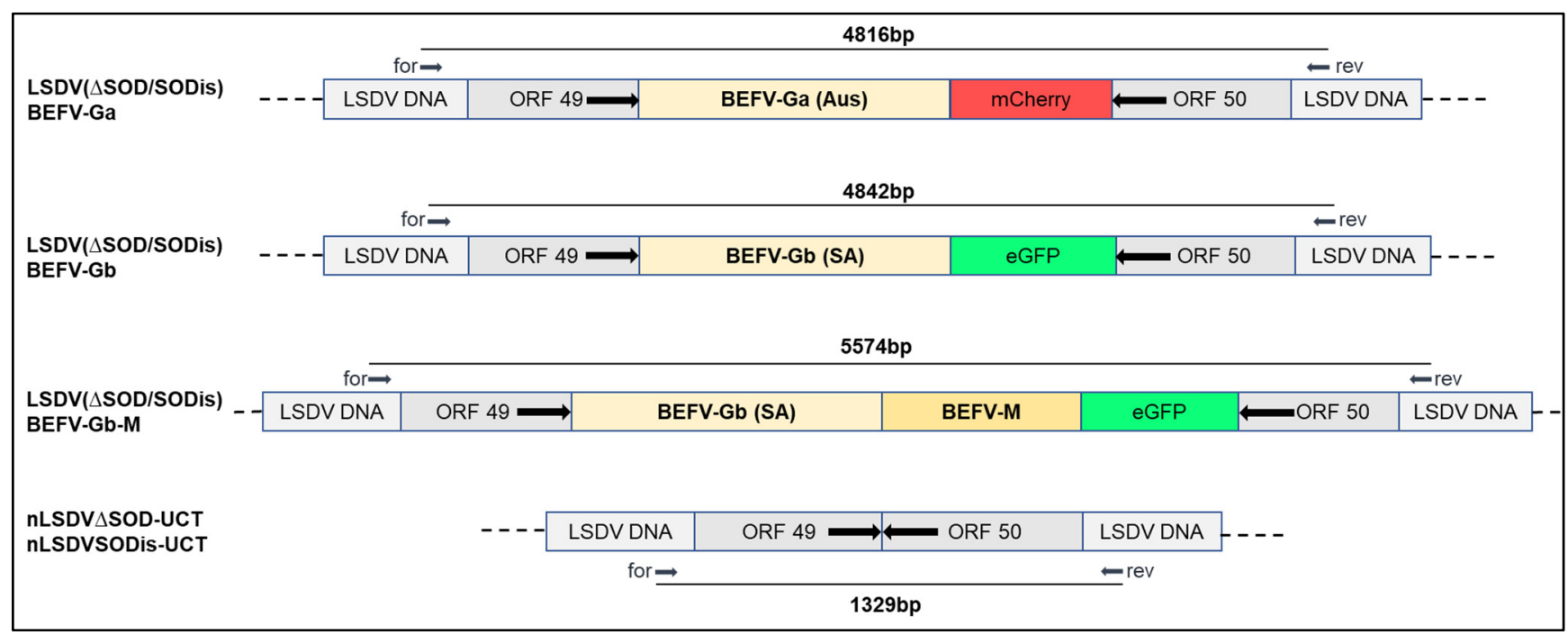

Figure 2. Diagrammatical representation of six dual LSDV-BEFV candidate vaccines constructed. The foreign gene cassettes were inserted into either nLSDV $\triangle$ SOD-UCT or nLSDVSODis-UCT, between LSDV ORFs 49 and 50. A BEFV G protein

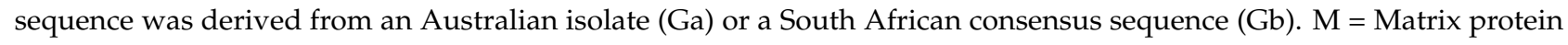
gene; mCherry and eGFP encode red and green fluorescent marker proteins, respectively. The positions of primer binding sites (for $=$ forward and rev $=$ reverse) are shown, as well as the PCR product sizes amplified from these primers.

\subsection{Neutralizing Antibody Responses Elicited by LSDV-BEFV Vaccine Candidates in a Rabbit Model}

The candidate vaccines were initially tested in a small animal model (rabbit) to determine which BEFV immunogens and LSDV vaccine backbones to take forward into cattle, a permissive host for LSDV.

\subsubsection{Comparison of Different BEFV Gene Inserts}

The same LSDV vector backbone was used to compare the three different BEFV gene inserts. As a control, one group of rabbits $(n=4)$ was inoculated with the vector backbone nLSDV $\triangle$ SOD-UCT. Five groups of rabbits $(n=5)$ were vaccinated with LSDV $(\Delta \mathrm{SOD}) \mathrm{BEFV-}$ Ga, LSDV(SODis)BEFV-Ga, LSDV( $\triangle S O D) B E F V-G b$, LSDV(SODis)BEFV-Gb, or LSDV $(\triangle \mathrm{SOD}) \mathrm{BEFV}-\mathrm{Gb}-\mathrm{M}$. After three vaccinations, all animals elicited positive neutralizing responses to LSDV (titres of $1 / 4$ to $1 / 256$ ) and BEFV (titres of $1 / 5$ to $1 / 320$ ). Figure $5 a$,b shows the BEFV neutralization titres to be higher $(1 / 20$ to $1 / 80)$ for rabbits vaccinated with LSDV $(\triangle \mathrm{SOD}) \mathrm{BEFV}-\mathrm{Gb}$ (African consensus BEFV G protein sequence) than rabbits vaccinated with $\mathrm{LSDV}(\triangle \mathrm{SOD}) \mathrm{BEFV}-\mathrm{Ga}$ (Australian BEFV G protein sequence) $(1 / 5$ to $1 / 10)$. The BEFV neutralization titres of rabbits vaccinated with LSDV $\triangle S$ SOD $) B E F V-G b-M$ were variable, ranging from $1 / 10$ to $1 / 320$. There was no statistical significant difference between LSDV( $\triangle \mathrm{SOD}) \mathrm{BEFV-Gb}$ and LSDV( $\triangle \mathrm{SOD}) \mathrm{BEFV-Gb-M.} \mathrm{Interestingly,} \mathrm{the} \mathrm{LSDV-BEFV}$ recombinants all elicited higher LSDV neutralization titres than the LSDV backbone alone (Figure 5a). A statistically significant difference in LSDV response was observed between nLSDV $\triangle$ SOD-UCT and LSDV( $\triangle$ SOD)BEFV-Gb-M (Figure 5c). LSDV( $\triangle S O D) B E F V-G b-M$ was chosen as the vaccine of choice to use in a comparison of the two LSDV backbones nLSDV $\triangle$ SOD-UCT and nLSDVSODis-UCT. 


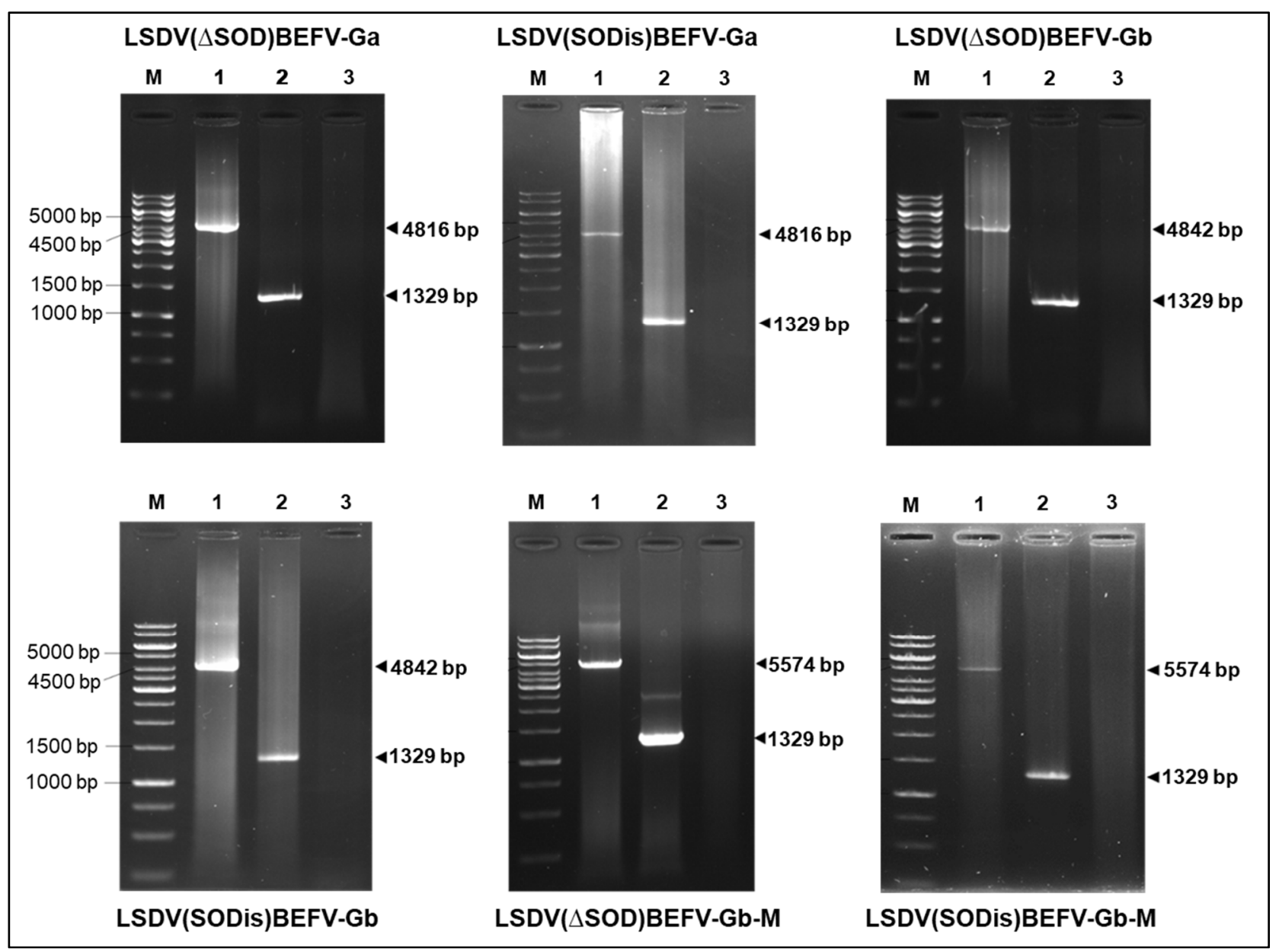

Figure 3. PCR confirmation of the recombinant LSDV-BEFV candidate vaccines. DNA was extracted from infected MDBK cells and subjected to PCR using forward (for) and reverse (rev) primers as indicated in Figure 2. Fragments were separated by electrophoresis on $0.8 \%$ agarose gels. $\mathrm{M}-$ GeneRuler $1 \mathrm{~kb}$ DNA Ladder (Thermo Fisher Scientific), lanes $1=$ vaccine of interest, as labelled above or below the images; lanes 2 = parent LSDV (nLSDV $\triangle$ SOD-UCT or nLSDVSODis-UCT) and lanes $3=$ uninfected cells.

3.2.2. Comparison of Different LSDV Backbones with the Same BEFV (Gb-M) Gene Inserts

A second experiment was performed in rabbits, following the same procedure, to compare the two different LSDV vector backbones with the BEFV Gb and M gene inserts (Figure 6). All rabbits, inoculated with either LSDV( $\triangle$ SOD)BEFV-Gb-M or LSDV(SODis) BEFV-Gb-M, elicited positive neutralizing responses to both LSDV and BEFV, but no difference could be observed between the two groups ( $p=0.1825$ for the BEFV neutralization titres and $p=0.318$ for the LSDV neutralization titres; Mann-Whitney test). Because rabbits are non-permissive to LSDV growth, it was hypothesized that a stronger response would be elicited in a bovine host, and a difference in the host response to the LSDV vector backbone may be observed, due to the presence or absence of the SOD gene homologue.

\subsection{Testing of LSDV( $\triangle S O D) B E F V-G b-M$ and LSDV(SODis)BEFV-Gb-M in Cattle}

Two groups $(n=10)$ of cattle were vaccinated twice, four weeks apart, with homologous LSDV( $\triangle$ SOD)BEFV-Gb-M or LSDV(SODis)BEFV-Gb-M vaccines and monitored daily for clinical signs of disease. Neither of the groups of cattle showed clinical signs of LSD, other than a raised temperature on day 1 post vaccination, which returned to normal the next day. There was no rise in temperature following the boost vaccination, given 32 days post initial vaccination. During the course of the experiment, two animals (ID 109 and 128), in the LSDV $(\triangle \mathrm{SOD}) \mathrm{BEFV}-\mathrm{Gb}-\mathrm{M}$ group, died prior to the boost vaccination and another 
four (ID 120, 121, 104 and 116), two from each group, died prior to the challenge at day 201. All deaths were unrelated to the vaccinations. Three animals died as a result of acute, haemorrhagic fibrinonecrotic pneumonia, probably caused by environmental stress. These were animals 128 (died on day 19 post vaccination), 104 (died on day 59 post vaccination) and 121 (died on day 117 post vaccination). Two animals succumbed to complications as a result of bloat. These were animals 109 (died on day 35 post vaccination) and 116 (died on day 200 post vaccination). Both animals had recurrent bloat and had been treated on several occasions before they died.

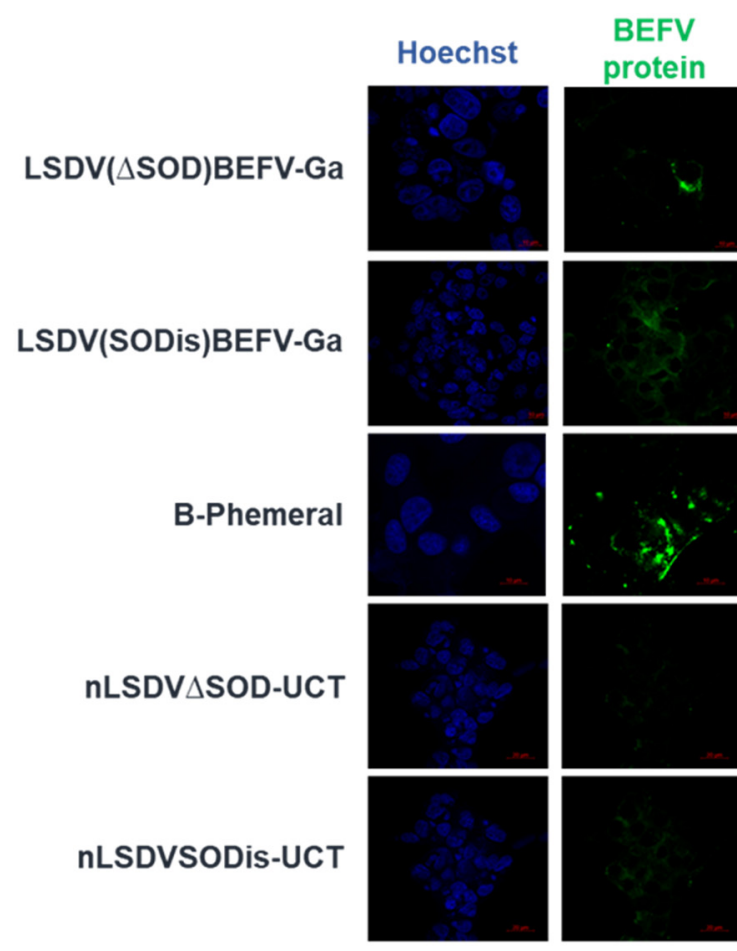

(a)

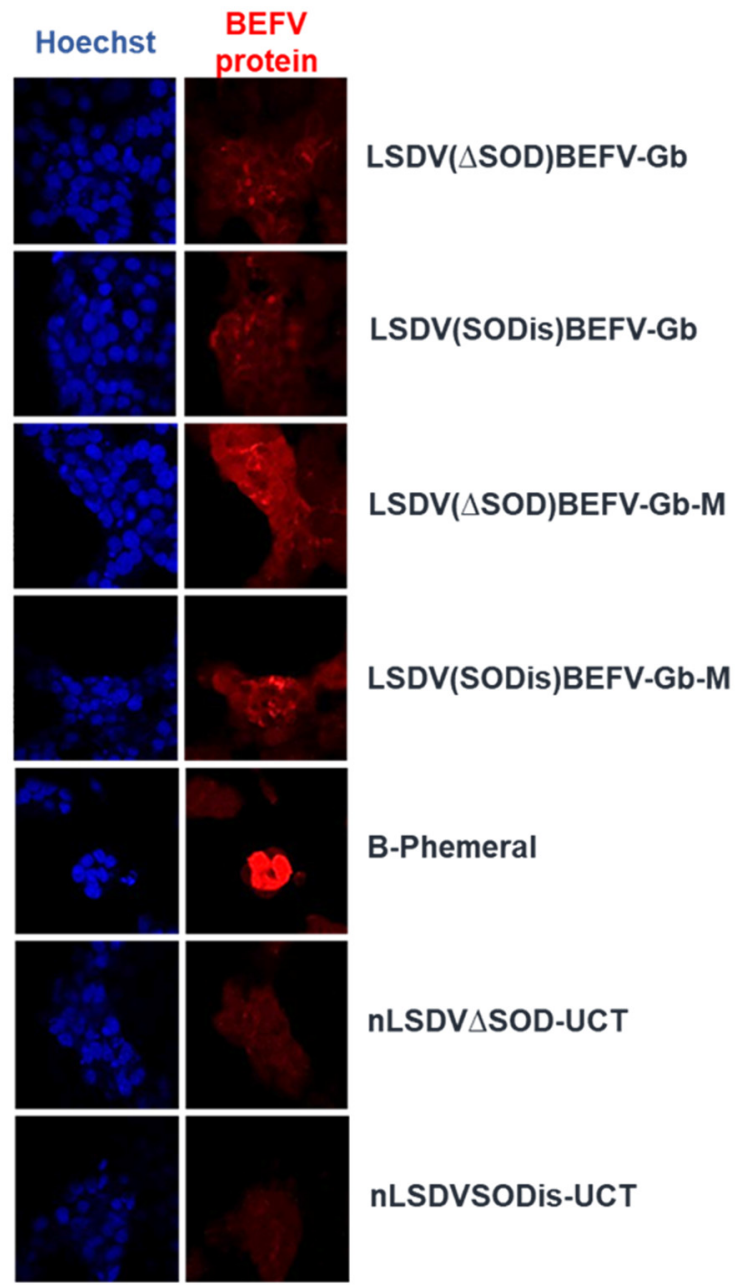

(b)

Figure 4. BEFV protein expression detected by immunofluorescence. MDBK cells grown on chamber slides were infected with B-Phemeral (positive control) and each of the vaccines at an MOI of 0.1 for $48 \mathrm{~h}$. The two parent LSDV vaccines (nLSDV $\triangle$ SOD-UCT and nLSDVSODis-UCT) were used as negative controls. Anti-B-Phemeral rabbit serum was used as the primary antibody for all samples (1:1000 dilution). (a) detection of BEFV Ga expression (green) using donkey anti-rabbit Alexa488 secondary antibody (1:500); (b) detection of BEFV Gb (red) and BEFV-Gb-M (red) using anti-rabbit CY3 secondary antibody (1:500). Nucleic acid was stained with Hoechst (blue). 


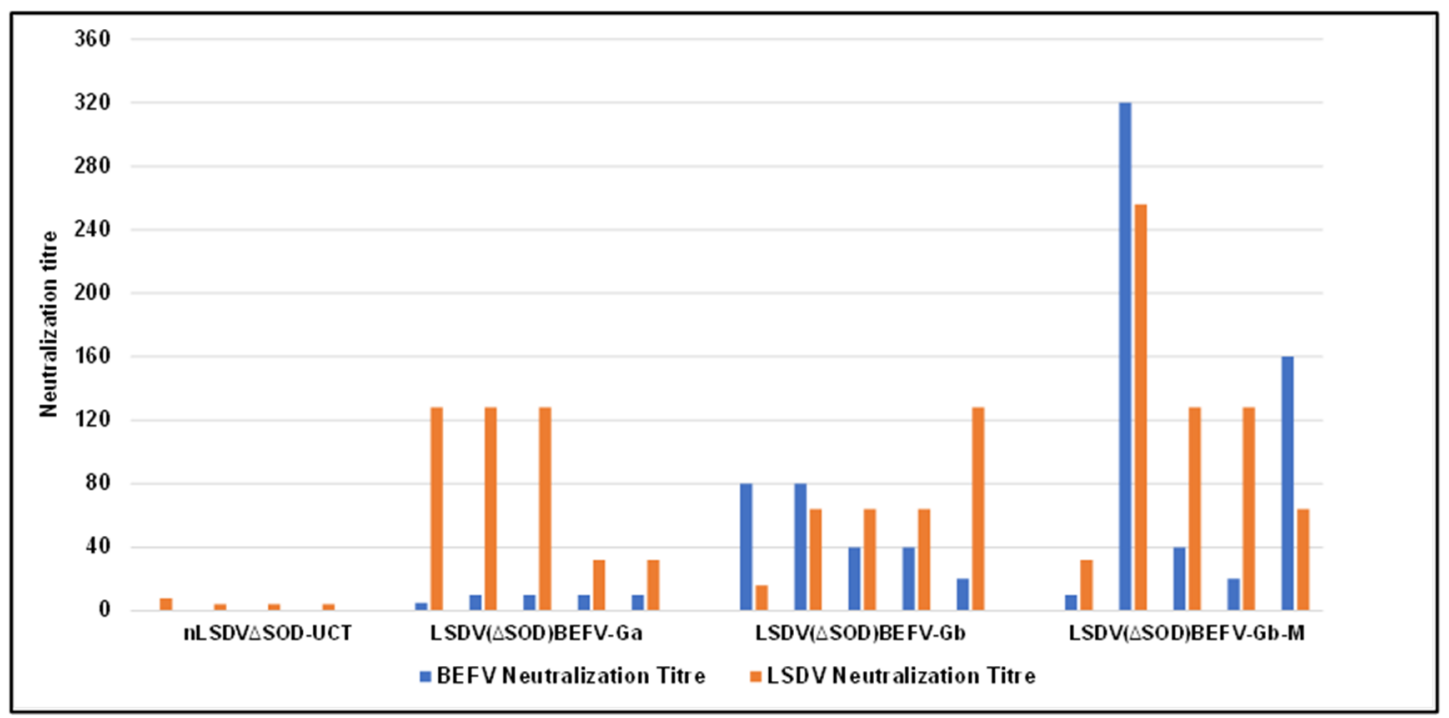

(a)

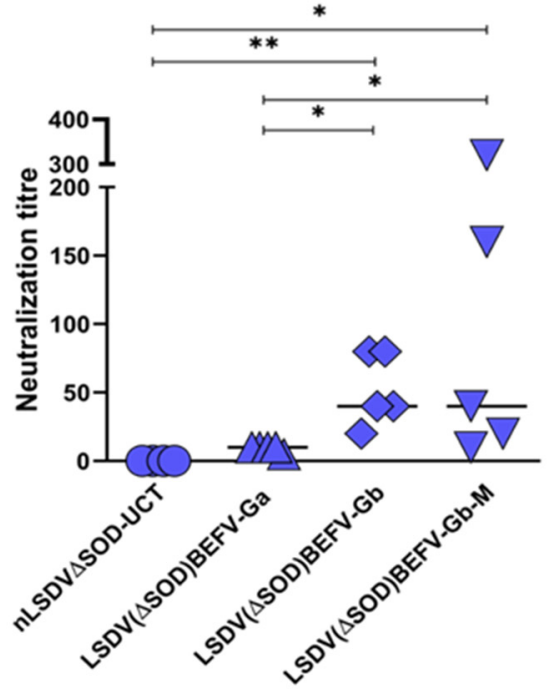

(b)

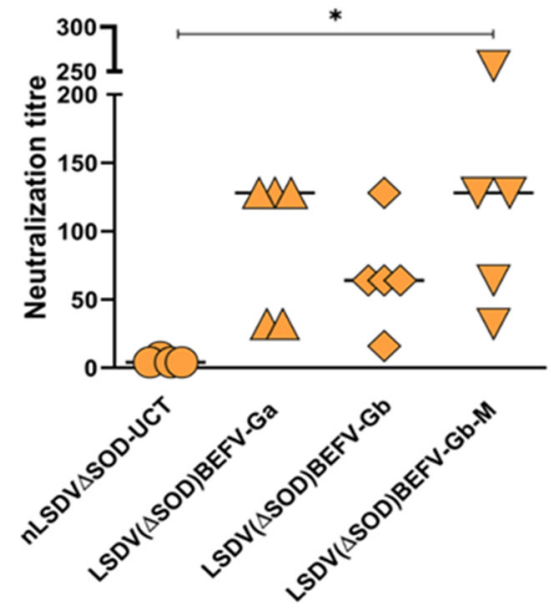

(c)

Figure 5. Comparison of dual vaccines expressing different BEFV gene inserts in a rabbit model. Rabbits were divided into groups of 5 , and each animal was inoculated intramuscularly with $10^{6} \mathrm{ffu}$ of the respective vaccines LSDV( $\left.\triangle S O D\right) B E F V-$ Ga, LSDV( $\triangle S O D) B E F V-G b$ and LSDV( $\triangle S O D) B E F V-G b-M$. nLSDV $\triangle S O D-U C T$ was given to group of 4 animals as a negative control for BEFV. Rabbits were given three doses of homologous vaccine at 28-day intervals and neutralization was tested on serum taken 14 days post final inoculation. Neutralization titres are expressed as the reciprocal of the dilution required to neutralize virus in $50 \%$ or more of wells of cells infected with BEFV or LSDV, respectively. (a) graph showing individual animal responses to both BEFV (blue) and LSDV (orange). BEFV (blue) and LSDV (orange) responses to the dual vaccines, expressing different BEFV inserts, were compared in $(\mathbf{b}, \mathbf{c})$ respectively. Statistical analysis was conducted using the Kruskal-Wallis test with Dunn's multiple comparison test. Horizontal lines indicate median values. ${ }^{*} p<0.05,{ }^{* *} p<0.01$. 


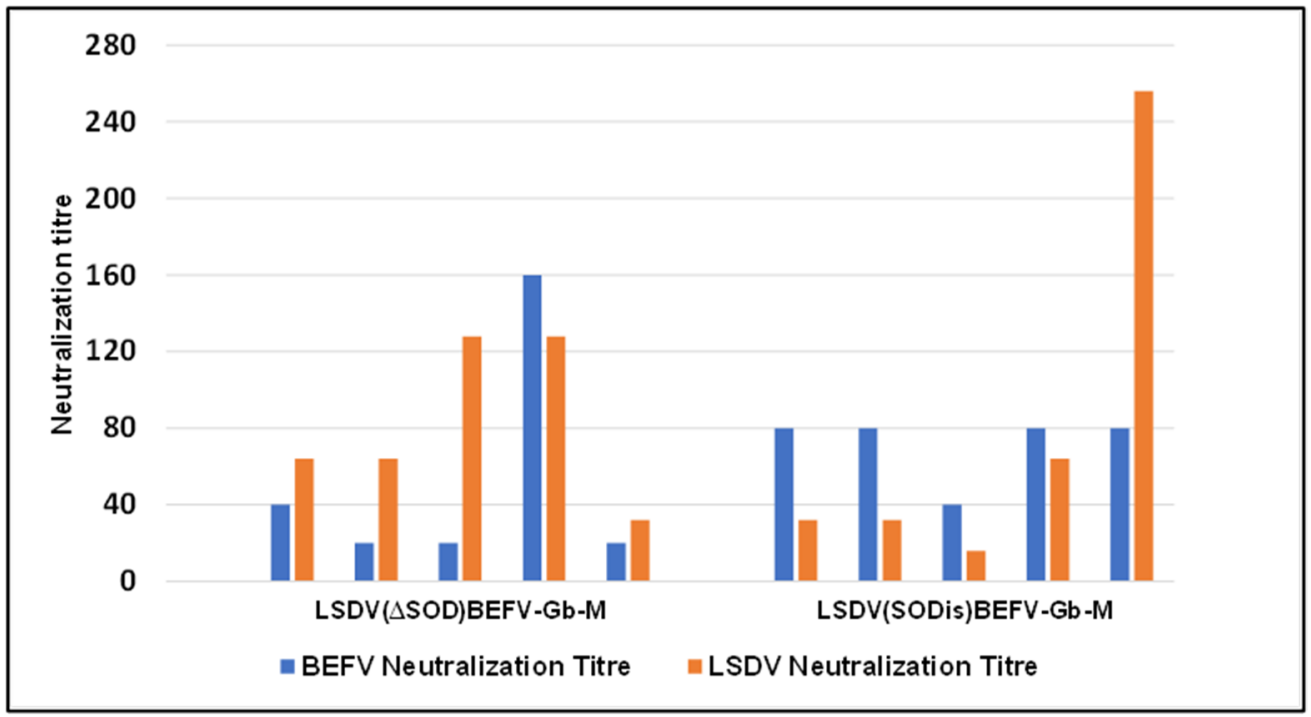

Figure 6. Comparison of two different LSDV vector backbones with the same BEFV gene inserts. Rabbits ( $n=5$ per group) were given three inoculations, 28 days apart, of either LSDV( $\triangle$ SOD)BEFVGb-M or LSDV(SODis)BEFV-Gb-M, intramuscularly, at a dose of $10^{6} \mathrm{ffu}$ per rabbit. Blood was taken 14 days after the final inoculation and serum was tested for neutralization of BEFV and LSDV. Neutralization titres are expressed as the reciprocal of the dilution required to neutralize virus in $50 \%$ or more of wells of cells infected with BEFV (blue) or LSDV (orange), respectively.

\subsubsection{Neutralization Responses to BEFV and LSDV}

Table 2 shows the neutralizing responses elicited at different time points post vaccination, post booster vaccination and post LSDV challenge. After one inoculation, only $4 / 20$ and $7 / 20$ animals developed neutralizing antibodies against BEFV and LSDV, respectively. Following the boost vaccination, all animals developed neutralizing responses to both BEFV and LSDV. Neutralizing antibodies against BEFV persisted for $>6$ months post boost in all vaccinated animals. All animals vaccinated with LSDV $(\triangle \mathrm{SOD}) \mathrm{BEFV}-\mathrm{Gb}-\mathrm{M}$ lost detectable LSDV neutralizing antibodies by day 201 ( $169 \mathrm{dpb})$, but $7 / 8$ of the animals vaccinated with LSDV(SODis)BEFV-Gb-M retained LSDV neutralizing antibodies until the time of challenge (169 dpb).

The increases in neutralization responses, against both BEFV and LSDV, were significantly higher for both groups of animals after the boost vaccination (Figure $7 \mathrm{a}, \mathrm{b}$ and Figure 8a,b, respectively). The differences between these responses in the two groups of animals were not statistically significant (Figure $7 \mathrm{c}, \mathrm{d}$ ). All vaccinated animals retained BEFV neutralization antibodies up until $169 \mathrm{dpb}$ (Figure $7 \mathrm{a}, \mathrm{b}$ ) with no significant difference between the two groups at $169 \mathrm{dpb}$ (Figure 7e).

Although LSDV neutralization titres did not differ significantly between the two groups at 14 and $30 \mathrm{dpb}$ (Figure 8a-d), there was a notable difference at day 201, when the group vaccinated with LSDV $(\triangle S O D) B E F V-G b-M$ showed no detectable neutralization response, whereas $7 / 8$ of the animals from the group vaccinated with LSDV(SODis)BEFVGb-M had positive LSDV neutralization responses (Figure 8e). Following challenge, all animals mounted rapid and strong LSDV neutralization responses by $14 \mathrm{dpc}$, which remained at the same level at $28 \mathrm{dpc}$ (Table 2 and Figure $8 \mathrm{a}, \mathrm{b}, \mathrm{f}, \mathrm{g}$ ). In comparison, the three naïve control animals developed increases in neutralizing antibody titres from 14 to $28 \mathrm{dpc}$ (Table 2 and Figure 8f,g). 
Table 2. Neutralization responses of cattle to BEFV (blue) and LSDV (orange). Titres are expressed as the reciprocal of the dilution required to neutralize the virus in $50 \%$ or more of wells of cells infected with BEFV or LSDV, respectively. The higher the titre the darker the shade. Titres $<1 / 5$ for BEFV and $<1 / 4$ for LSDV were regarded as -ve. pre-im = pre-immunisation, $\mathrm{dpv}=$ days post vaccination, $\mathrm{dpb}=$ days post boost, $\mathrm{dpc}=$ days post challenge; asterisks show animals which developed

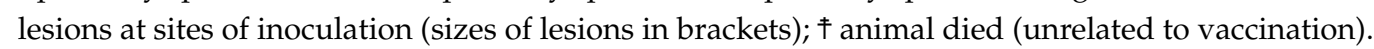

\begin{tabular}{|c|c|c|c|c|c|c|c|c|c|c|c|c|c|c|c|}
\hline \multirow{2}{*}{$\begin{array}{c}\text { Animal ID } \\
\text { Day }\end{array}$} & \multicolumn{7}{|c|}{ BEFV Neutralization Titre } & \multicolumn{8}{|c|}{ LSDV Neutralization Titre } \\
\hline & 0 & 14 & 28 & 46 & 62 & 201 & 229 & 0 & 14 & 28 & 46 & 62 & 201 & 215 & 229 \\
\hline & $\begin{array}{l}\text { pre- } \\
\text { im }\end{array}$ & $\begin{array}{c}14 \\
\mathrm{dpv}\end{array}$ & $\begin{array}{c}28 \\
\mathrm{dpv}\end{array}$ & $\begin{array}{c}14 \\
\mathrm{dpb}\end{array}$ & $\begin{array}{c}30 \\
\mathrm{dpb}\end{array}$ & $\begin{array}{l}169 \\
d p b\end{array}$ & $\begin{array}{l}197 \\
\text { dpb }\end{array}$ & pre-im & $\begin{array}{c}14 \\
\mathrm{dpv}\end{array}$ & $\begin{array}{c}28 \\
\mathrm{dpv}\end{array}$ & $\begin{array}{c}14 \\
\mathrm{dpb}\end{array}$ & $\begin{array}{c}30 \\
d p b\end{array}$ & $\begin{array}{c}0 \\
\mathrm{dpc}\end{array}$ & $\begin{array}{c}14 \\
\mathrm{dpc}\end{array}$ & $\begin{array}{c}28 \\
\mathrm{dpc}\end{array}$ \\
\hline \multicolumn{16}{|c|}{ LSDV $(\triangle \mathrm{SOD})$ BEFV-Gb-M } \\
\hline $1-16110$ & -ve & - -ve & 5 & 320 & 160 & 160 & 160 & -ve & -ve & -ve & 8 & 32 & -ve & 256 & 256 \\
\hline $1-16112$ & -ve & -ve & -ve & 80 & 20 & 5 & 5 & -ve & -ve & -ve & 64 & 64 & -ve & 128 & 64 \\
\hline $1-16113$ & -ve & -ve & 5 & 40 & 40 & 40 & 40 & -ve & 16 & 8 & 64 & 64 & -ve & 256 & 256 \\
\hline $\begin{array}{c}1-16115^{*} \\
(2.5 \mathrm{~cm})\end{array}$ & -ve & 10 & 10 & 160 & 40 & 40 & 40 & -ve & 8 & 8 & 32 & 32 & -ve & 256 & 256 \\
\hline $1-16120$ & -ve & -ve & $-\mathrm{ve}$ & 160 & 40 & † & キ & -ve & 16 & 8 & 64 & 64 & 申 & キ & † \\
\hline $1-16121$ & -ve & -ve & -ve & 80 & 40 & 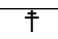 & $\neq$ & -ve & -ve & -ve & 8 & 8 & $\neq$ & 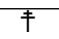 & $\neq$ \\
\hline $1-16123$ & -ve & -ve & -ve & 40 & 40 & 40 & 40 & -ve & 32 & 8 & 16 & 16 & -ve & 512 & 256 \\
\hline 1-16 129 & -ve & -ve & -ve & 160 & 160 & 10 & 10 & -ve & -ve & -ve & 64 & 64 & -ve & 512 & 256 \\
\hline $1-16109$ 甲 & -ve & -ve & -ve & † & † & $\neq$ & $\neq$ & -ve & -ve & -ve & $\neq$ & $\neq$ & 申 & 申 & † \\
\hline $1-16128^{7}$ & -ve & -ve & $\mp$ & † & 7 & † & 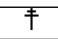 & -ve & -ve & 7 & † & 7 & † & 7 & † \\
\hline \multicolumn{16}{|c|}{ LSDV(SODis) BEFV-Gb-M } \\
\hline 1-16 101 & -ve & -ve & -ve & 80 & 80 & 80 & 80 & -ve & 4 & $-\mathrm{ve}$ & 8 & 8 & 8 & 128 & 128 \\
\hline $1-16102$ & -ve & -ve & -ve & 160 & 160 & 40 & 40 & -ve & -ve & -ve & 64 & 64 & 32 & 64 & 128 \\
\hline $\begin{array}{c}1-16103^{*} \\
(2.2 \mathrm{~cm})\end{array}$ & -ve & -ve & -ve & 80 & 40 & 40 & 20 & -ve & -ve & -ve & 32 & 32 & 8 & 256 & 128 \\
\hline $1-16104$ & -ve & -ve & -ve & 20 & 20 & $\neq$ & $\neq$ & -ve & -ve & -ve & -ve & 8 & 申 & $\neq$ & $\neq$ \\
\hline $1-16105$ & -ve & -ve & -ve & 40 & 40 & 20 & 10 & -ve & -ve & -ve & 16 & 16 & 4 & 64 & 64 \\
\hline $1-16107$ & -ve & -ve & -ve & 160 & 80 & 10 & 5 & -ve & -ve & -ve & 16 & 32 & -ve & 64 & 32 \\
\hline $\begin{array}{l}1-16111^{*} \\
(1.8 \mathrm{~cm})\end{array}$ & -ve & 5 & 20 & 160 & 160 & 160 & 160 & -ve & 16 & 32 & 128 & 256 & 64 & 128 & 64 \\
\hline $1-16116$ & -ve & -ve & -ve & 160 & 160 & $\neq$ & $\neq$ & -ve & -ve & -ve & 16 & 8 & † & キ & † \\
\hline $\begin{array}{l}1-16122 * \\
(3.2 \mathrm{~cm})\end{array}$ & -ve & -ve & -ve & 80 & 80 & 40 & 40 & -ve & -ve & 16 & 64 & 32 & 32 & 32 & 64 \\
\hline $1-16126$ & -ve & -ve & -ve & 40 & 40 & 40 & 40 & -ve & 4 & 16 & 32 & 32 & 32 & 256 & 256 \\
\hline $1-16$ & & & & & & & & & & & & & $\begin{array}{c}0 \\
\mathrm{dpc}\end{array}$ & $\begin{array}{c}14 \\
\mathrm{dpc}\end{array}$ & $\begin{array}{c}28 \\
\mathrm{dpc}\end{array}$ \\
\hline \multicolumn{16}{|c|}{ Naïve Control Animals } \\
\hline $1-161^{*}(>6 \mathrm{~cm})$ & & & & & & & & & & & & & -ve & 128 & 512 \\
\hline $6^{*}(>6 \mathrm{~cm})$ & & & & & & & & & & & & & -ve & 16 & 64 \\
\hline $8^{*}(>6 \mathrm{~cm})$ & & & & & & & & & & & & & -ve & 32 & 512 \\
\hline
\end{tabular}

\subsubsection{Binding Antibody Responses to BEFV}

Sera, from time points 14 and $30 \mathrm{dpb}$, were tested for BEFV binding antibodies, using pre-immune sera as a negative control $\left(\mathrm{OD}_{450}<0.2\right)$ and a kit positive control $\left(\mathrm{OD}_{450}>0.3\right)$. The ELISA plates were coated with a BEFV G protein monomer of Asian origin, which included the conserved linear epitope 1 . All animals produced binding antibodies at 14 and $30 \mathrm{dpb}$ (Figure 9a,b), with no significant differences between the groups vaccinated with LSDV( $\triangle$ SOD)BEFV-Gb-M and LSDV(SODis)BEFV-Gb-M.

\subsubsection{Protection of Vaccinated Cattle from LSDV Challenge}

The cattle vaccinated with LSDV( $\triangle$ SOD)BEFV-Gb-M and LSDV(SODis)BEFV-Gb-M were challenged with a dose of $10^{7} \mathrm{TCID}_{50}$ virulent LSDV at day 201 (almost 6 months post boost). A control group of three naïve animals was also challenged in the same way. All control animals developed localized swelling at the site of injection at $4 \mathrm{dpc}$ and a raised temperature for over a week post infection. Figure 10a shows the control animals at $14 \mathrm{dpc}$ and Figure 10b shows their rectal temperatures taken over a period of 6 weeks (two weeks prior to challenge and 4 weeks post challenge). In addition, the control group of animals became sensitive to touch from day 4 post infection and this lasted for approximately 10 days. Both groups of vaccinated animals developed a fever one day post challenge (data not shown), but temperatures subsided after one day. No other signs of illness were presented, showing that the vaccinated animals were protected against LSD. 


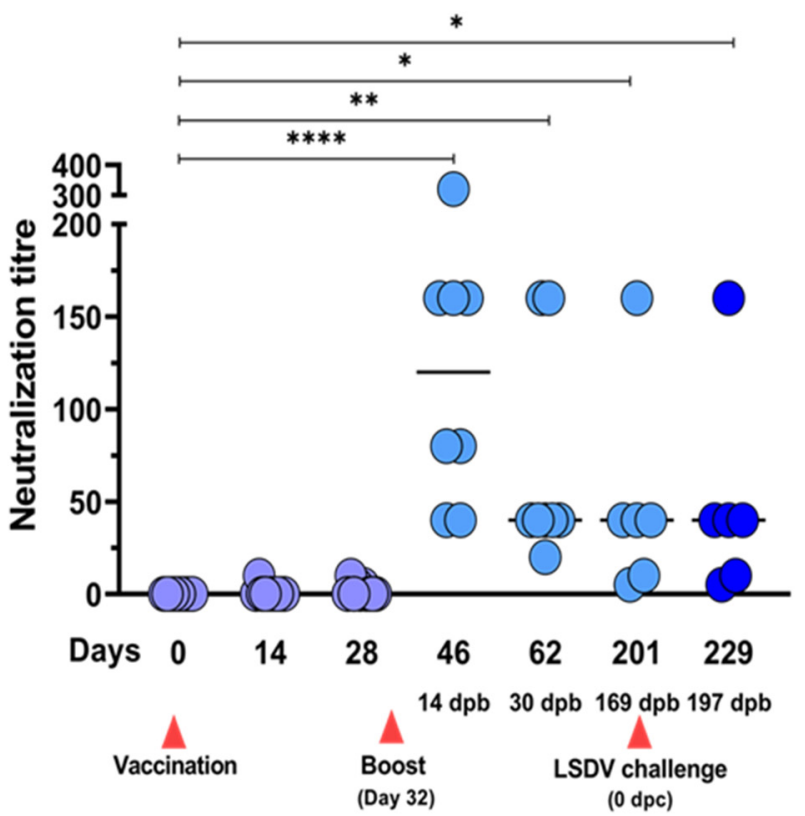

(a)

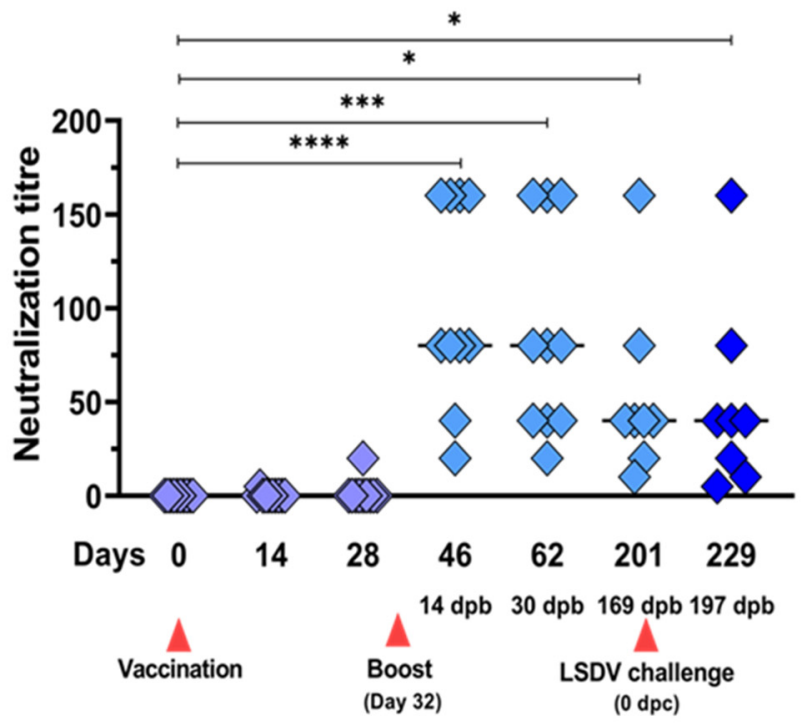

(b)

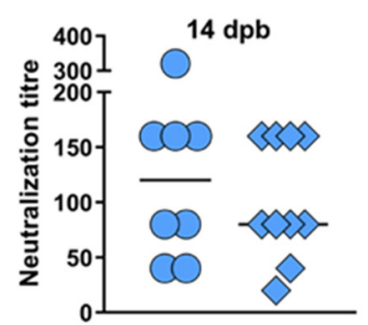

(c)

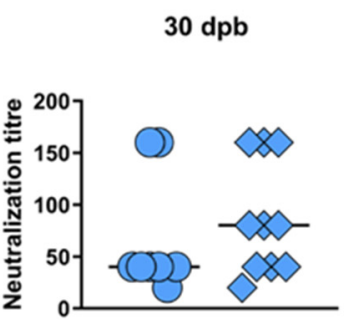

(d)

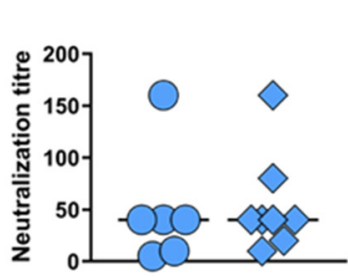

(e)

Figure 7. BEFV neutralization responses elicited by LSDV( $\triangle \mathrm{SOD}) B E F V-G b-\mathrm{M}$ (circles) and LSDV(SODis)BEFV-Gb-M (diamonds) in cattle. Two groups of cattle $(n=10)$ were inoculated subcutaneously with $10^{5} \mathrm{TCID}_{50}$ per animal and boosted with $5 \times 10^{4}$ TCID $_{50} 32$ days later. The animals were bled at two-week intervals and the serum tested for neutralizing responses to BEFV. Scatter plots show neutralization responses to LSDV( $\triangle S O D) B E F V-G b-M(a)$ and LSDV(SODis)BEFV-Gb$\mathrm{M}$ (b) over time; different colour shades indicate responses after one (lilac) or two (light blue) vaccinations or LSDV challenge (royal blue). (c-e) show comparative BEFV responses to LSDV( $\triangle$ SOD)BEFV-Gb-M (circles) and LSDV(SODis)BEFV-Gb-M (diamonds) at 14, 30 and $169 \mathrm{dpb}$, respectively. $\mathrm{dpb}=$ days post boost. Statistical analyses were conducted using the Kruskal-Wallis test with Dunn's multiple comparison test $(\mathbf{a}, \mathbf{b})$ and Mann-Whitney $U$ test (c-e). Horizontal lines indicate median values. ${ }^{*} p<0.05,{ }^{* *} p<0.01,{ }^{* * *} p<0.001,{ }^{* * * *} p<0.0001$.

\subsubsection{T Cell Responses to BEFV and LSDV Post LSDV Challenge}

Cattle challenged with virulent LSDV were tested for $\mathrm{CD}^{+}$and $\mathrm{CD} 8^{+} \mathrm{T}$ cell responses prior to challenge $(0 \mathrm{dpc})$ and, at weekly intervals, post LSDV challenge $(7,14$ and $21 \mathrm{dpc})$. Whole blood was stimulated with either LSDV or BEFV. 


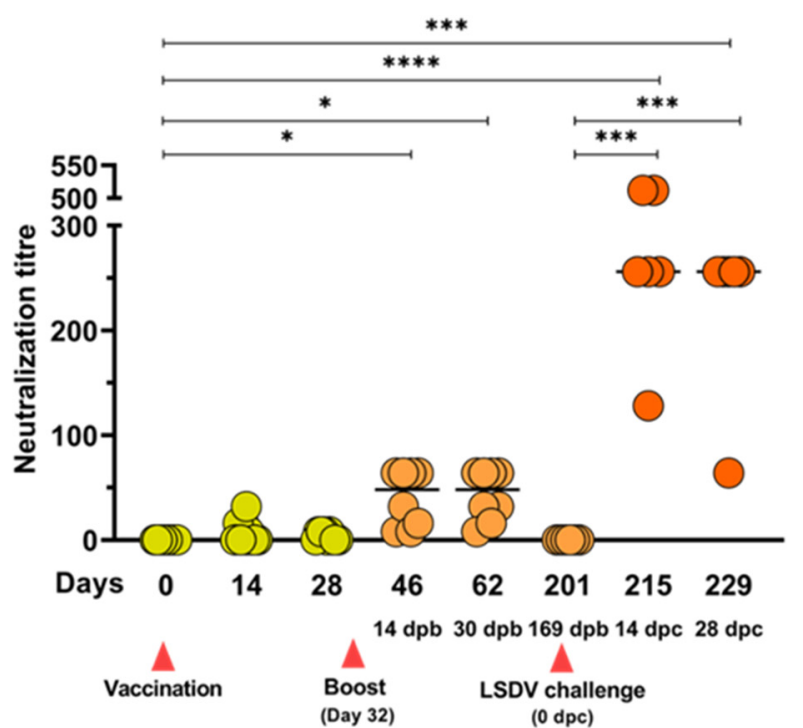

(a)

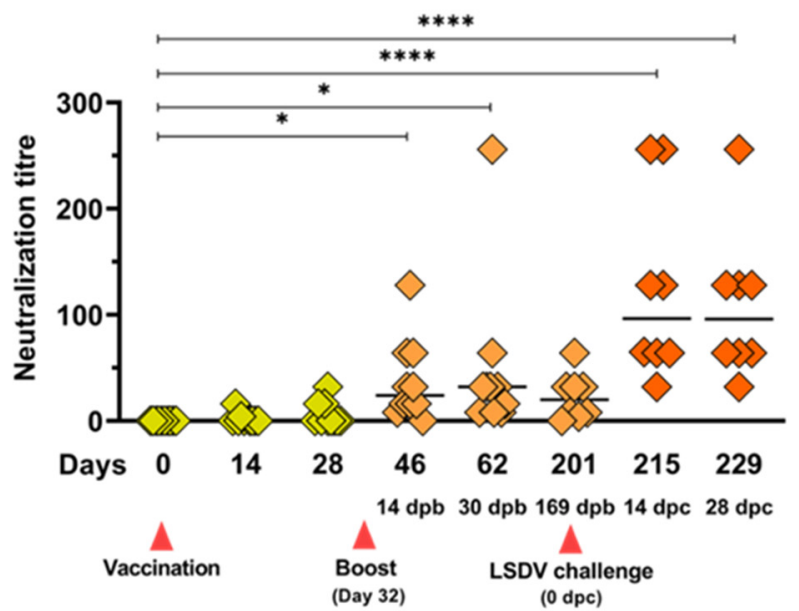

(b)

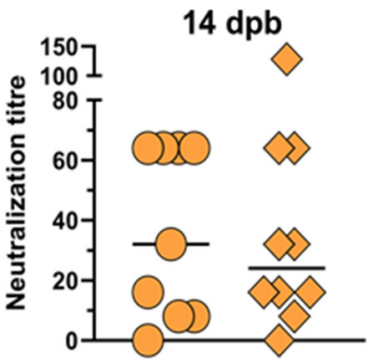

(c)

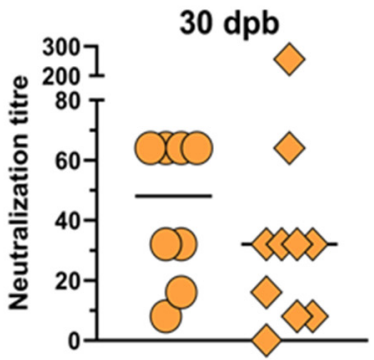

(d)

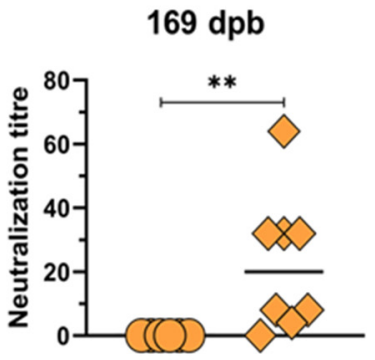

(e)

$14 \mathrm{dpc}$

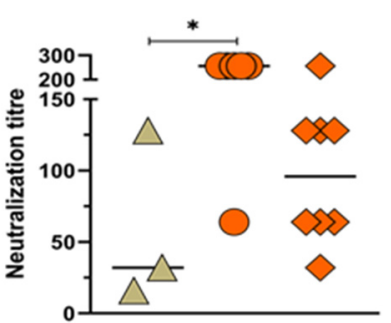

(f) $28 \mathrm{dpc}$

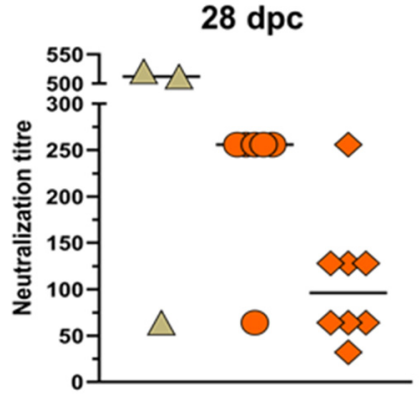

(g)

Figure 8. LSDV neutralization responses elicited by LSDV( $\triangle \mathrm{SOD}) \mathrm{BEFV-Gb-M}$ (circles) and LSDV(SODis)BEFV-Gb-M (diamonds) in cattle. Two groups of cattle $(n=10)$ were inoculated with $10^{5} \mathrm{TCID}_{50}$ per animal, subcutaneously, and boosted with $5 \times 10^{4} \mathrm{TCID}_{50} 32$ days later. The animals were challenged with $10^{7} \mathrm{TCID}_{50}$ virulent LSDV 169 days post boost. Scatter plots show LSDV neutralization responses to LSDV( $\triangle S O D) B E F V-G b-M(a)$ and LSDV(SODis)BEFV-Gb-M (b) over time; (c-e) show comparative LSDV responses to LSDV( $\triangle$ SOD)BEFV-Gb-M (circles) and LSDV(SODis)BEFV-Gb-M (diamonds) at 14, 30 and $169 \mathrm{dpb}$, respectively; (f,g) show LSDV responses to the naive control animals (triangles), LSDV( $\triangle \mathrm{SOD}) \mathrm{BEFV-Gb-}$ $\mathrm{M}$ (circles) and LSDV(SODis)BEFV-Gb-M (diamonds) groups, 14 and $28 \mathrm{dpc}$, respectively. Different colour shades indicate responses after one (lime) or two (orange) vaccinations or LSDV challenge (red). $\mathrm{dpb}=$ days post boost, $\mathrm{dpc}=\mathrm{days}$ post challenge. Statistical analyses were conducted using the Kruskal-Wallis test with Dunn's multiple comparison test (a,b,f,g) and Mann-Whitney U test (c,d,e). Horizontal lines indicate median values. ${ }^{*} p<0.05,{ }^{* *} p<0.01,{ }^{* * *} p<0.001,{ }^{* * * *} p<0.0001$. 


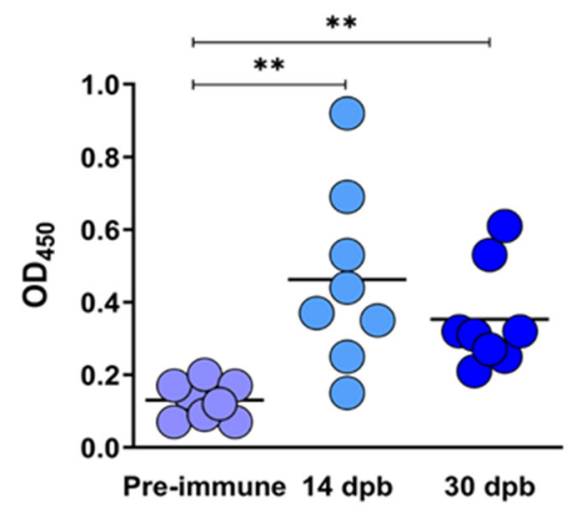

(a)

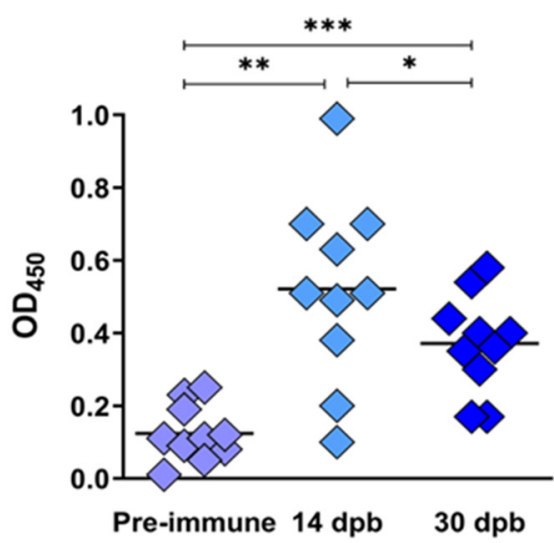

(b)

Figure 9. BEFV binding antibody responses elicited by LSDV $\triangle \triangle S O D) B E F V-G b-M$ (circles) and LSDV(SODis)BEFV-Gb-M (diamonds) in cattle. Sera from the two groups of cattle were tested using a commercial ELISA kit (Unibiotest, Wuhan, China), for binding antibodies to BEFV G protein monomer of Asian lineage. Scatter plots show binding antibody responses to BEFV measured at $450 \mathrm{~nm}\left(\mathrm{OD}_{450}\right)$ in cattle vaccinated with LSDV( $\left.\triangle S O D\right)$ BEFV-Gb-M (a) and LSDV(SODis)BEFV-Gb$\mathrm{M}$ (b) at pre-vaccination (lilac), $14 \mathrm{dpb}$ (light blue) and $30 \mathrm{dpb}$ (royal blue). Statistical analyses were conducted using repeated measures one-way ANOVA with Tukey's multiple comparison test. Horizontal lines indicate median values. ${ }^{*} p<0.05,{ }^{* *} p<0.01,{ }^{* * *} p<0.001$.
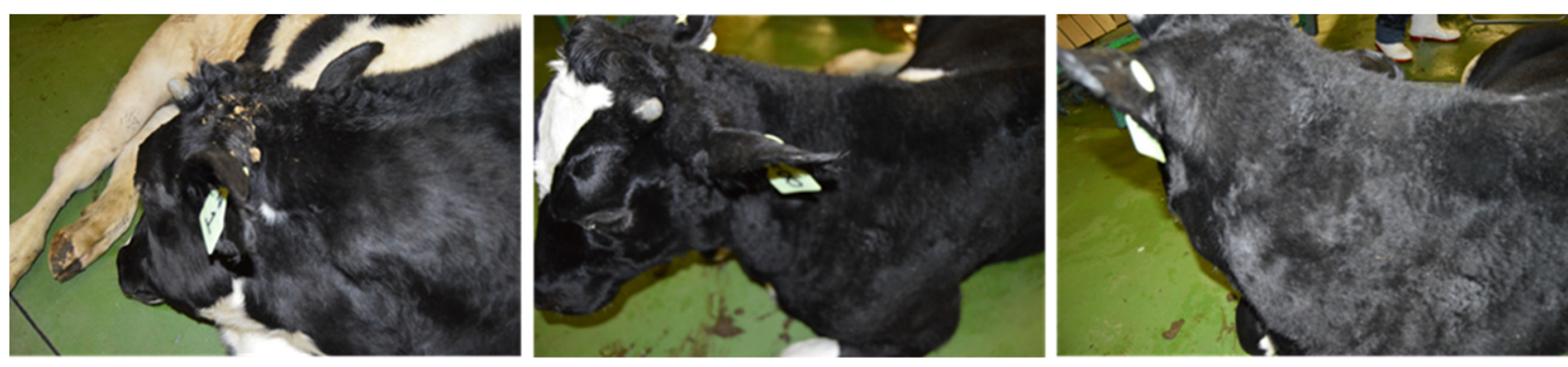

(a)
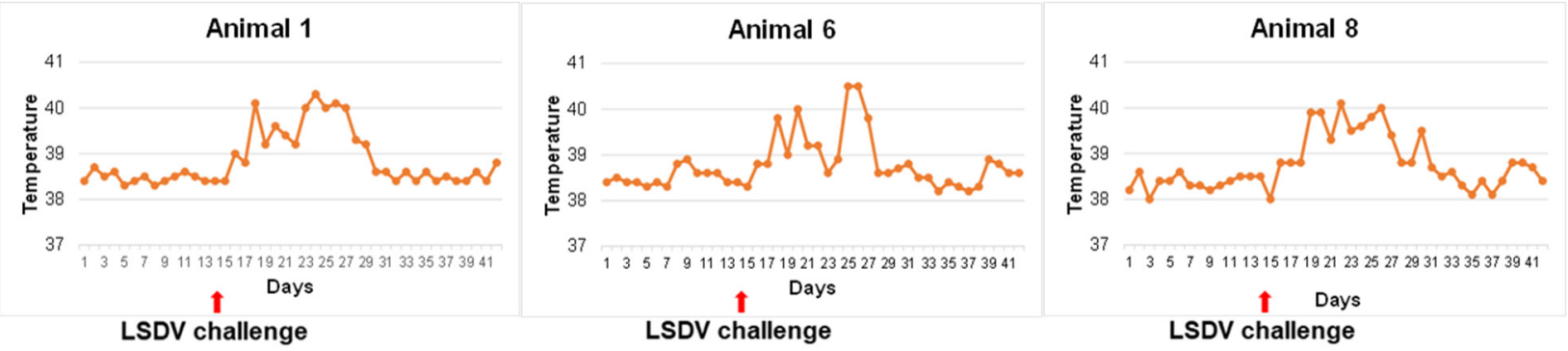

(b)

Figure 10. Naïve control group of cattle challenged with virulent LSDV. Three LSDV-negative cattle were infected with $10^{7}$ TCID $_{50}$ virulent LSDV and observed for 28 days thereafter. (a) Localized swelling photographed 14 days post infection; (b) temperatures of the three control animals for a period of 14 days prior to challenge and 28 days post challenge. 


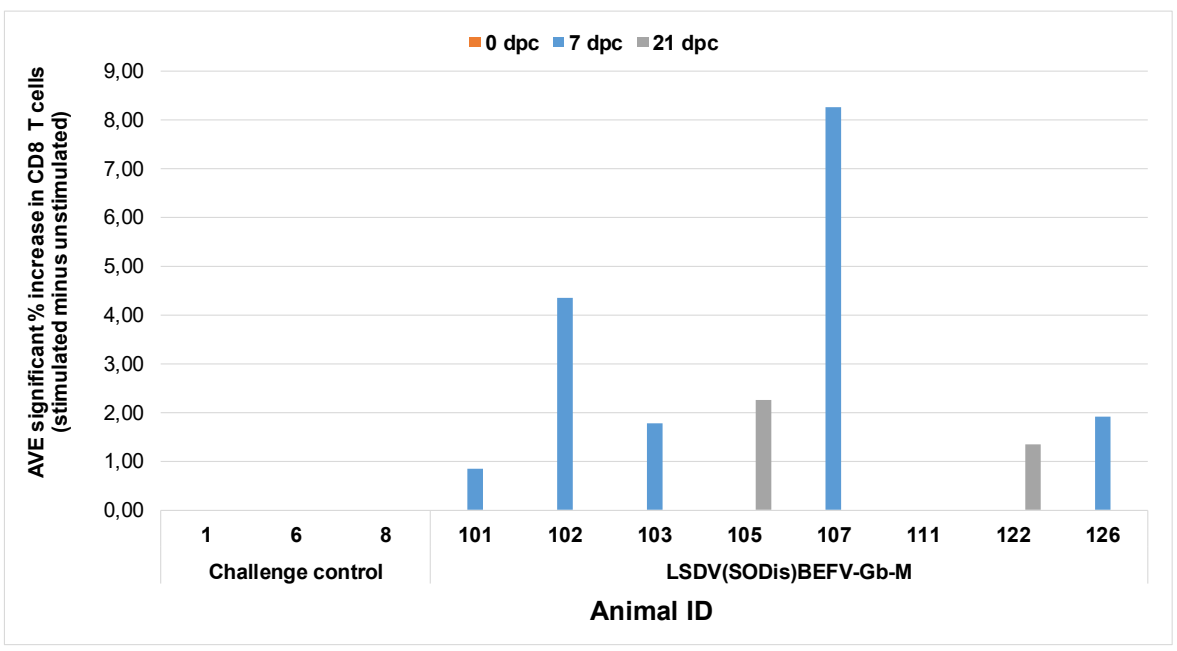

Figure 11. $\mathrm{CD}^{+} \mathrm{T}$ cell responses to BEFV following virulent LSDV challenge. Whole blood was stimulated with BEFV for $24 \mathrm{~h}$ and $\mathrm{CD}^{+} \mathrm{T}$ cells were measured. Only significant average $\% \mathrm{CD} 8^{+}$ $\mathrm{T}$ cells compared to control stimulants are shown. Animals 1, 6 and 8 were naïve control animals; animals 101, 102, 103, 105, 107, 111, 122 and 126 were all vaccinated with LSDV(SODis)BEFV-Gb-M. None of the animals vaccinated with $\operatorname{LSDV}(\triangle \mathrm{SOD}) \mathrm{BEFV}-\mathrm{Gb}-\mathrm{M}$ gave positive responses and there were no positive responses at $0 \mathrm{dpc}$. $\mathrm{dpc}=$ days post challenge.

\section{T Cell Responses to BEFV Post Challenge}

Vaccinated cattle challenged with virulent LSDV did not develop $\mathrm{CD}^{+} \mathrm{T}$ cell responses to BEFV (data not shown). However, a significant $\mathrm{CD}^{+} \mathrm{T}$ cell response, as compared to control stimulants, was detected at $7 \mathrm{dpc}$ in $5 / 8$ animals and in two animals at $21 \mathrm{dpc}$ (animal ID 105 and 122) tested in the group vaccinated with LSDV(SODis)BEFVGb-M (Figure 11), but not in the group vaccinated with LSDV( $\triangle S O D) B E F V-G b-M$. The variable responses between individual animals per group and at time points are expected for outbred animals. These cells also produced low levels of IFN- $\gamma$ although at a percentage increase of less than one. This indicates that a CD8 T cell response was activated by vaccination with the $\mathrm{LSDV}$ (SODis)BEFV-Gb-M vaccine that is specific to BEFV antigens.

\section{T Cell Responses to LSDV Post Challenge}

IFN $-\gamma^{+} \mathrm{CD} 4^{+} \mathrm{T}$ cells, stimulated by LSDV, were produced by $14 \mathrm{dpc}$ in all animals (Figure 12a,b). Most animals showed increased levels of IFN- $\gamma^{+} \mathrm{CD} 4^{+} \mathrm{T}$ cells compared to the challenge control $0 \mathrm{dpc}$ but, due to one outlier in the challenge control, were not significant (Figure 12a,b). There was no significant difference between the responses elicited by the three different groups, namely, naïve control animals, LSDV( $\triangle S O D) B E F V-G b-M-$ and LSDV(SODis)BEFV-Gb-M)-vaccinated animals.

A cellular immune response to LSDV mediated by $\mathrm{CD} 8^{+} \mathrm{T}$ cells was predominantly detected in PBMCs at $21 \mathrm{dpc}$ in 5/6 animals tested in the group vaccinated with the LSDV $(\triangle \mathrm{SOD})$ BEFV-Gb-M vaccine, in $8 / 8$ animals in the group vaccinated with the LSDV (SODis)BEFV-Gb-M vaccine and 2/3 animals in the challenge control group (Figure 12c,d). These $\mathrm{CD} 8^{+} \mathrm{T}$ cells also produced low levels of IFN- $\gamma$.

Collectively, this indicates that both $\mathrm{CD} 4^{+}$and $\mathrm{CD} 8^{+} \mathrm{T}$ cell responses were activated against LSDV after challenge. 
(a)
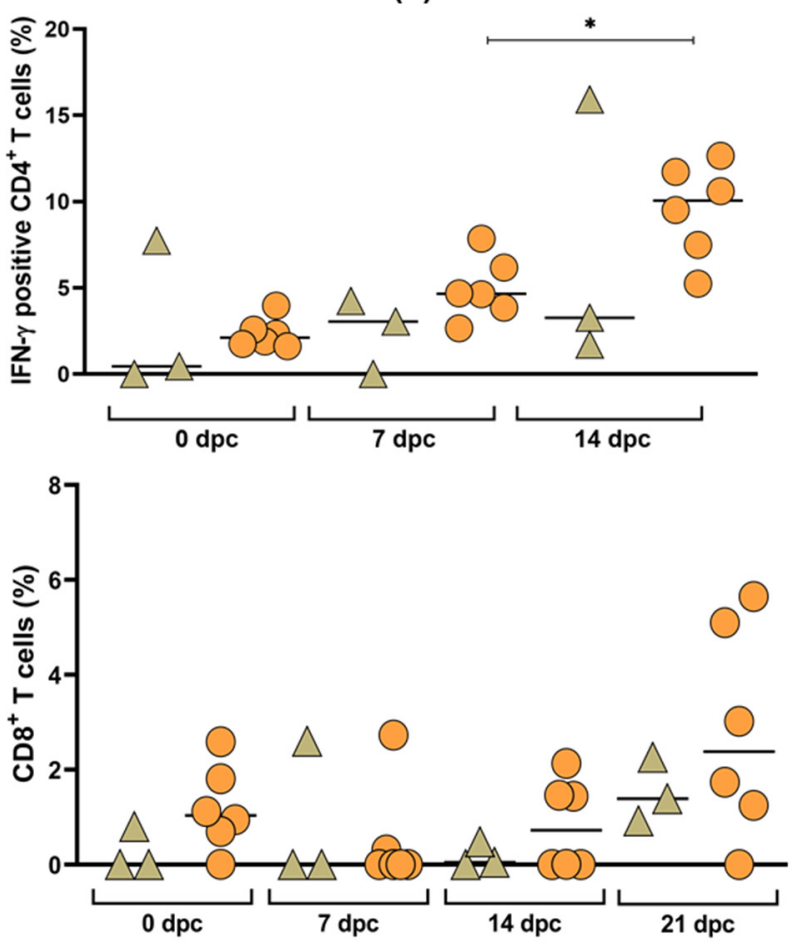

(c) (b)
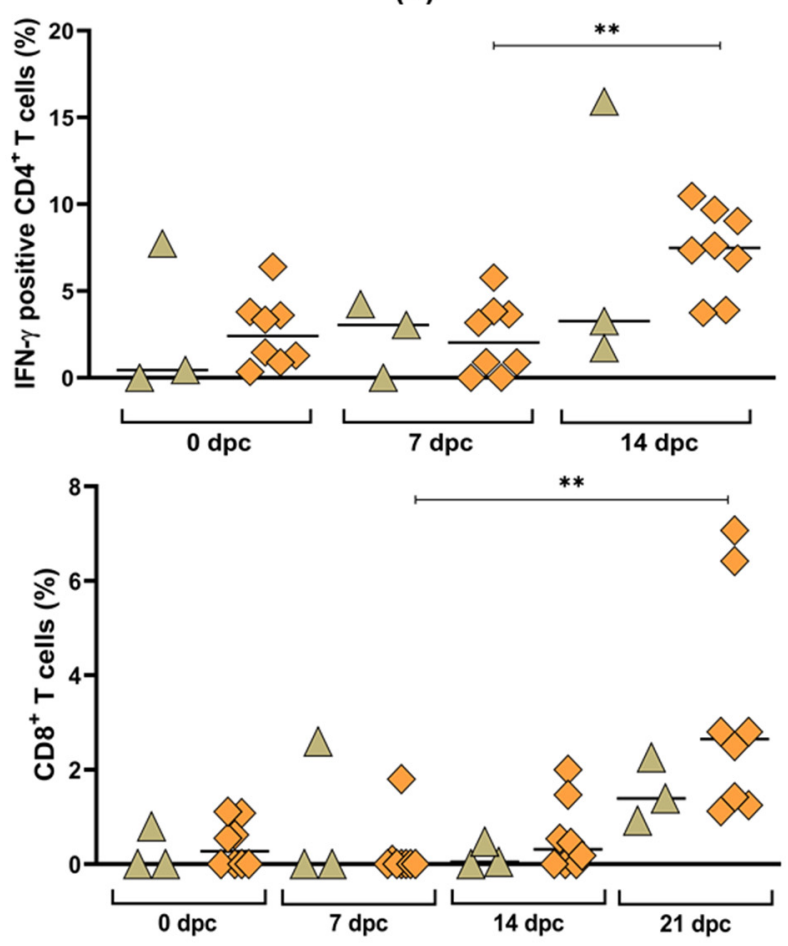

(d)

\section{$\triangle$ Naïve $\bigcirc$ LSDV( $\triangle$ SOD)BEFV-Gb-M $\diamond$ LSDV(SODis)BEFV-Gb-M}

Figure 12. T cell responses to LSDV following virulent LSDV challenge. Whole blood was stimulated with LSDV for $24 \mathrm{~h}$ and IFN $\gamma$-secreting $\mathrm{CD}^{+}$and CD8 ${ }^{+} \mathrm{T}$ cells were measured. $(\mathbf{a}, \mathbf{b})$ the average $\% \mathrm{IFN} \gamma$ - secreting $\mathrm{CD} 4^{+} \mathrm{T}$ cells from $0-14 \mathrm{dpc}$ from cattle vaccinated with LSDV( $\triangle S O D) B E F V-G b-M$ (circles) and LSDV(SODis)BEFV-Gb-M (diamonds), respectively; (c,d) the average $\% \mathrm{CD}^{+} \mathrm{T}$ cells from $0-21 \mathrm{dpc}$ from cattle vaccinated with LSDV( $\triangle$ SOD)BEFV-Gb-M (circles) and LSDV(SODis)BEFVGb-M (diamonds), respectively; the green diamonds represent unvaccinated naïve cattle. Statistical analyses were conducted using Welch one-way ANOVA with Dunnett's T3 multiple comparison test $(\mathbf{a}, \mathbf{b})$ and Kruskal-Wallis test with Dunn's multiple comparison test $(\mathbf{c}, \mathbf{d})$. Horizonal lines indicate median values. ${ }^{*} p<0.05,{ }^{* *} p<0.01$.

\section{Discussion}

Despite the availability of vaccines against BEF and LSD, these two diseases remain a threat to the cattle industry. Several different platforms have been used to make BEFV vaccines [10], with inactivated and live attenuated vaccines being the most widely used. Inactivated BEFV vaccines require multiple doses and, even then, are not fully protective [42,43]. A combination of live attenuated followed by killed vaccine [44] is used in Japan [11], the vaccines being based on local strains of BEFV. The live attenuated BPhemeral, derived from an African BEFV isolate, is used in South Africa in a two-dose regimen [12].

The $G$ protein is recognized as being antigenic [11,13-16] and has been used as a protein vaccine [13]. Secreted forms of the BEFV G protein, lacking the transmembrane portion of the protein, are being investigated as subunit vaccines [45]. Virus vectors, such as rabies [46], Newcastle Disease virus [40], vaccinia virus [14] and LSDV [47], which express the BEFV G protein, continue to be explored as platforms for BEFV vaccine development. Proof of concept that a recombinant poxvirus could be used to protect cattle is given by Hertig et al., (1996) who demonstrated that the vaccinia virus expressing BEFV G protein could protect cattle from BEFV challenge [14]. Since then, LSDV has been explored as a vector for novel BEFV vaccines $[47,48]$. All previous research on poxvirus recombinants expressing BEFV proteins is based on the Australian BEFV G protein $[14,47,48]$. The LSDVBEFV recombinants were made many years ago, using the LSDV Neethling vaccine as a 
backbone, and included the metabolic selection gene, guanine phosphoribosyl transferase, which is not present in the recombinants described in this paper. In addition, the thymidine kinase [47] or ribonucleotide reductase [48] genes were disrupted for insertion of the foreign gene cassette. Disruption of these genes further attenuates LSDV, which is not desirable. These previous studies on LSDV-BEFV recombinants could not demonstrate protection from BEFV challenge. In our study, an intergenic site, located between two highly conserved open reading frames, LSDV ORFs 49 and 50, was used. This site was chosen as a stable site of insertion, which would not cause any gene disruption in LSDV. No antibiotic resistance genes were incorporated into the recombinants.

Recent evidence has shown that the G protein sequences of African BEFV isolates differ from those from other parts of the world $[12,18]$ and sequence alignment has revealed differences in amino acid sequences in the known antigenic epitopes of the $G$ protein between the African isolates and those from other parts of the world [12]. However, the linear G1 epitope has only one conserved amino acid difference (I496V), suggesting it may confer some cross-protection. Rabbits vaccinated with LSDV $(\triangle \mathrm{SOD}) \mathrm{BEFV}-\mathrm{Ga}$, which expresses an Australian $G$ protein, developed low titres $(1 / 5$ to $1 / 10)$ of neutralizing antibodies against B-Phemeral. The cross neutralization could be attributed to the conservation of the G1 epitope. An ELISA test, based on a subunit Asian G protein containing the G1 epitope, was used to test vaccinated cattle sera for binding antibodies to this BEFV subunit $G$ protein. All animals, which were vaccinated with vaccines expressing the South African $G$ protein, elicited antibodies which bound to the Asian G protein (Figure 9). These results are not surprising as antigenic cross-reactivity has been shown between isolates from Australia, China, Japan, Kenya, Nigeria and South Africa [11].

Rabbits vaccinated with recombinant LSDV expressing the South African consensus G protein, LSDV $\triangle S$ SOD)BEFV-Gb, elicited a significantly increased BEFV neutralization response compared to those vaccinated with LSDV( $\triangle \mathrm{SOD}) \mathrm{BEFV-Ga} \mathrm{(Figure} 5 \mathrm{~b}$ ). In contrast, there was no significant difference in LSDV neutralization titres between these two groups (Figure $5 c$ ), and the LSDV $\triangle S$ SOD)BEFV-Ga group tended towards a slightly higher LSDV neutralization response. The stronger BEFV neutralization responses are most likely due to the identity of all four antigenic epitopes conserved amongst the African isolates. The strong BEFV neutralizing responses induced by Gb confirmed that the design of the South Africa consensus $G$ protein was appropriate.

The highest neutralization titres were generated by rabbits vaccinated with LSDV ( $\triangle \mathrm{SOD}$ )BEFV-Gb-M; however, there was no statistical significance between the groups to definitively conclude that the $\mathrm{M}$ protein gene improved the response. Whether the $\mathrm{M}$ protein aids the formation of virus-like particles or not is still to be determined. The two candidate vaccines LSDV( $\triangle \mathrm{SOD}$ )BEFV-Gb-M and LSDV(SODis)BEFV-Gb-M were compared to determine whether the absence or presence, respectively, of the LSDV SODhomologue gene would influence immunogenicity. No difference was found between the two groups of rabbits immunized with the different vaccines. The strong neutralization responses elicited against both BEFV and LSDV in a non-permissive (rabbit) host justified testing the vaccine candidates in cattle, the natural host for LSDV. The two vaccines, LSDV( $\triangle S O D$ )BEFV-Gb-M and LSDV(SODis)BEFV-Gb-M, expressing both Gb and M, were therefore tested in cattle.

The permissive bovine animal model was thought to be more sensitive to the effects of the LSDV SOD-homologue on immunogenicity and clinical response to the vaccine. An earlier pilot experiment to compare nLSDV $\triangle$ SOD-UCT and nLSDVSODis-UCT in the same animal suggested that there could be a difference with respect to pathology caused by the two different LSDV backbones [29], but no differences were observed between the two vaccines LSDV( $\triangle$ SOD)BEFV-Gb-M and LSDV(SODis)BEFV-Gb-M in this study. Lesions were produced at the sites of inoculation in $1 / 10$ and $3 / 10$ animals vaccinated with LSDV $(\triangle \mathrm{SOD})$ BEFV-Gb-M and LSDV(SODis)BEFV-Gb-M, respectively, and these resembled the lesions regularly observed in cattle vaccinated with the Neethling strain of LSDV. 
A drawback of this study was the inability to test the vaccines in a virulent BEFV challenge experiment, due to the unavailability of virulent BEFV challenge virus. The preparation of virulent BEFV challenge virus has been a major hurdle in testing BEFV vaccines for other groups too $[14,40,47]$. However, we were able to demonstrate that the two vaccines, LSDV( $\triangle$ SOD)BEFV-Gb-M and LSDV(SODis)BEFV-Gb-M, elicited neutralizing antibodies to BEFV after two inoculations given four weeks apart, with titres ranging from $1 / 20$ to $1 / 320$ at $14 \mathrm{dpb}$. The BEFV neutralization responses were durable for at least six months in all vaccinated animals. This is encouraging as BEFV neutralizing antibodies have been shown to wane after four months post vaccination with inactivated BEFV [44]; and a neutralization titre of $1 / 5$ or $1 / 6$ has been associated with protection against BEFV infection [49]. The BEFV neutralization titres ranged from $1 / 5$ to $1 / 160$ at day 229 (197 dpb) in this study (Table 1).

Although all animals, vaccinated with either LSDV( $\triangle$ SOD)BEFV-Gb-M or LSDV(SODis) BEFV-Gb-M, developed strong antibody responses to BEFV, the group vaccinated with LSDV(SODis)BEFV-Gb-M, and not that vaccinated with LSDV( $\triangle S O D) B E F V-G b-M$, gave an increased $\mathrm{CD}^{+} \mathrm{T}$ cell response at seven days post virulent LSDV challenge. The BEFV memory cells induced by vaccination will reside in secondary lymph organs. These CD ${ }^{+}$ $\mathrm{T}$ cells are likely in circulation in PBMCs post challenge for immune surveillance induced by the innate detection of a viral infection after the LSDV challenge. Since there was no $\mathrm{BEFV}$ detected in the host by these cells, clonal expansion of BEFV specific $\mathrm{CD} 8^{+} \mathrm{T}$ cells did not occur in vivo and thus were only detected in PBMC in vitro for a limited time.

This study, using the two LSDV vaccine backbones, nLSDV $\triangle$ SOD-UCT and nLSDVSODis-UCT [29], showed both vaccines to be safe and immunogenic, eliciting strong humoral (neutralizing antibody) and T cell responses to LSDV, as well as to provide protection (100\%) against virulent LSDV challenge. All animals in the naïve control group developed clinical symptoms of LSD, indicating that the protection was due to vaccination.

The duration of LSDV neutralizing antibodies differed according to the vaccine backbone. Although all animals in both groups were protected against challenge, the group vaccinated with LSDV(SODis)BEFV-Gb-M showed a more durable LSDV neutralizing responses compared to the group vaccinated with LSDV( $\triangle \mathrm{SOD}) \mathrm{BEFV}-\mathrm{Gb}-\mathrm{M}$. All animals developed LSDV neutralizing antibodies by $30 \mathrm{dpb}$, with SNT titres ranging from $1 / 8$ to $1 / 256$. At day 201 (169 days post boost), all animals vaccinated with LSDV( $\Delta$ SOD)BEFVGb-M had dropped LSDV neutralizing antibody titre to undetectable levels, whereas 7/8 animals vaccinated with LSDV(SODis)BEFV-Gb-M had positive neutralizing antibody titres $(1 / 4$ to $1 / 64)$. Interestingly, post challenge, the LSDV( $\triangle$ SOD)BEFV-Gb-M group developed higher neutralizing antibody responses than the LSDV(SODis)BEFV-Gb-M by 14 days post challenge. A possible explanation for this could be that the challenge virus replicated in the animals with undetectable neutralizing antibodies and the higher viral load stimulated a higher response needed to control the challenge. The neutralization titres remained constant until the end of the experiment at $28 \mathrm{dpc}$. In comparison, the naïve control group of animals showed a slower increase in neutralization titres, with higher titres at $28 \mathrm{dpc}$ compared to $14 \mathrm{dpc}$. This confirms the memory response in previously vaccinated animals compared to the naïve animals.

The $\mathrm{T}$ cell responses to LSDV were predominantly $\mathrm{CD} 4^{+}$in nature, which developed by $14 \mathrm{dpc}$. The $\mathrm{CD} 8^{+} \mathrm{T}$ cell responses to LSDV were lower than the CD4+ responses and developed later, at $21 \mathrm{dpc}$ (Figure 12). The $\mathrm{CD}^{+}$cells were the main producers of IFN- $\gamma$. The more delayed response of the LSDV specific $\mathrm{CD} 8^{+} \mathrm{T}$ cell kinetics compared to that of BEFV is likely due to homing of the cells to the site of infection after challenge and detection in circulating PBMCs once the virus at the challenge site was cleared.

An interesting observation with repeated LSDV-BEFV inoculations was the ability to boost antibody responses to both BEFV and LSDV. This was also observed in our previous study on a LSDV-rabies recombinant [50], and LSDV re-vaccination of cattle has been shown to significantly increase antibody titre to LSDV [51]. One of the concerns with viral vectored vaccines is neutralization of the vector, preventing use of the same vector 
for boosting responses to the transgene product [52]. However, multiple immunizations with LSDV did not result in prevention of infection with the boosting virus. The challenge experiment would indicate that neutralizing responses played a role in controlling infection together with $\mathrm{T}$ cell responses. This is an indication that LSDV could be used to deliver multivalent vaccines, or alternatively, different vaccines at different times without the immunity to LSDV preventing infection with the recombinant virus.

The recombinant vaccines described in this paper are potential candidates for dual vaccines against LSD and BEF. The two recombinants LSDV( $\triangle$ SOD)BEFV-Gb-M and LSDV(SODis)BEFV-Gb-M warrant further testing in the field as they were both safe at the dosage tested, which was 10 times higher than the standard LSDV vaccine dose. The cattle used in this experiment were Friesian dairy cattle, which were expected to be the most sensitive cattle to LSDV vaccines. No evidence of Neethling associated disease was observed. However, the vaccines need to be tested in different species of cattle to further determine dosage, immunogenicity and safety. We hypothesize that the recombinants expressing the BEFV Ga protein would be more suited to use in Asia and Australia; and those vaccines expressing BEFV Gb would be more suitable for use in Africa.

\section{Conclusions}

Six candidate vaccines have been developed to simultaneously immunize cattle against $\mathrm{BEF}$ and LSD. In a rabbit model, all vaccines elicited neutralizing responses to the live attenuated B-Phemeral vaccine strain of BEFV, including the vaccine candidates expressing the Australian BEFV Ga gene. With Africa in mind, greater focus was on those vaccines based on the consensus African sequence of BEFV $(\mathrm{Gb})$ as vaccines expressing the $\mathrm{Gb}$ protein are likely to be more protective in the African setting. It could not conclusively be shown that the BEFV M gene improved immunogenicity, but the highest neutralization titres were produced by rabbits vaccinated with LSDV expressing both Gb and M protein genes. The two candidate vaccines, LSDV( $\triangle \mathrm{SOD}$ )BEFV-Gb-M and LSDV(SODis)BEFVGb-M, elicited neutralizing responses to both BEFV and LSDV in cattle. In addition, they conferred protection against virulent LSDV challenge, inducing rapid, strong neutralizing responses post challenge as well as $\mathrm{CD}^{+}$and $\mathrm{CD}^{+} \mathrm{T}$ cell responses.

\section{Patents}

A provisional patent application has been filed for the vaccine LSDV(SODis)BEFV-GbM, application number: SPOORSA-sa_cases.0153757.PA176615/P.

Author Contributions: Conceptualization, N.D., R.O. and A.-L.W.; Data curation, N.D., A.S., W.d.M. and A.P.; Formal analysis, N.D., R.O., H.M., A.S., W.d.M., A.P. and A.-L.W.; Funding acquisition, A.-L.W.; Investigation, N.D., R.O., H.M., A.S., W.d.M., P.M., A.P., T.N., A.v.S., P.K., L.H. and A.-L.W.; Methodology, N.D., R.O., H.M., A.S., W.d.M., P.M., A.P., T.N., A.v.S. and P.K.; Project administration, N.D. and L.H.; Resources, A.-L.W.; Supervision, N.D., L.H. and A.-L.W.; Visualization, N.D., A.S., W.d.M. and P.M.; Writing—original draft, N.D.; Writing—review and editing, N.D., A.S., W.d.M., A.P. and A.-L.W. All authors have read and agreed to the published version of the manuscript.

Funding: This research was funded by the Technology Innovation Agency, project No. TBS14-0020C; A.-L.W. is funded by the National Research Foundation of South Africa, Grant No. 64,815.

Institutional Review Board Statement: The study was conducted according to the guidelines of the Declaration of Helsinki. Authorization to grow LSDV in eggs was granted by the University of Cape Town Animal Ethics committee, (018/012) on the 22 June 2018. Ethics approval to test the candidate vaccines in rabbits was granted from the University of Cape Town (AEC 018_039) on the 28 November 2018, Stellenbosch University (UCT-DOUG-2019) on the 2 April 2019 and the South African Department of Agriculture, Forestry and Fisheries (DAFF) (Ref: 12/11/1/7/1) on the 30 October 2017. Ethics approval for the cattle experiment which was performed at the ARC institute-Onderstepoort Veterinary Research (Transboundary Animal Diseases) was granted by the South African Department of Agriculture, Land Reform and Rural Development (DALRRD), study number: TADP-S-20/02, [DALRRD Ref no: 12/11/1/1], on the 30 September 2020. 
Informed Consent Statement: Not applicable.

Data Availability Statement: Not applicable.

Acknowledgments: Noel Markgraaff is acknowledged for doing the rabbit work at Stellenbosch University.

Conflicts of Interest: A patent application has been filed on the LSDV vector backbones, international application number PCT/IB2019/054090 (agency reference PA166012PCT) and on LSDV(SODis)BEFVGb-M, application number: SPOORSA-sa_cases.0153757.PA176615/P. The funders had no role in the design of the study; in the collection, analyses, or interpretation of data; in the writing of the manuscript, or in the decision to publish the results.

\section{References}

1. Akakpo, A.J. Three-day fever. Rev. Sci. Tech. 2015, 34, 525-538. [CrossRef]

2. Hamdi, J.; Munyanduki, H.; Omari Tadlaoui, K.; El Harrak, M.; Fassi Fihri, O. Capripoxvirus Infections in Ruminants: A Review. Microorganisms 2021, 9, 902. [CrossRef] [PubMed]

3. Namazi, F.; Khodakaram Tafti, A. Lumpy skin disease, an emerging transboundary viral disease: A review. Vet. Med. Sci. 2021, 7, 888-896. [CrossRef] [PubMed]

4. Gupta, T.; Patial, V.; Bali, D.; Angaria, S.; Sharma, M.; Chahota, R. A review: Lumpy skin disease and its emergence in India. Vet. Res. Commun. 2020, 44, 111-118. [CrossRef] [PubMed]

5. Tuppurainen, E.S.; Oura, C.A. Review: Lumpy skin disease: An emerging threat to Europe, the Middle East and Asia. Transbound. Emerg. Dis. 2012, 59, 40-48. [CrossRef] [PubMed]

6. European Food Safety, A.; Calistri, P.; De Clercq, K.; Gubbins, S.; Klement, E.; Stegeman, A.; Cortinas Abrahantes, J.; Marojevic, D.; Antoniou, S.E.; Broglia, A. Lumpy skin disease epidemiological report IV: Data collection and analysis. EFSA J. 2020, 18, e06010. [CrossRef] [PubMed]

7. Saltykov, Y.V.; Kolosova, A.A.; Filonova, N.N.; Chichkin, A.N.; Feodorova, V.A. Genetic Evidence of Multiple Introductions of Lumpy Skin Disease Virus into Saratov Region, Russia. Pathogens 2021, 10, 716. [CrossRef]

8. St George, T.D. Bovine ephemeral fever: A review. Trop. Anim. Health Prod. 1988, 20, 194-202. [CrossRef]

9. Lee, F. Bovine Ephemeral Fever in Asia: Recent Status and Research Gaps. Viruses 2019, 11, 412. [CrossRef]

10. Walker, P.J. Bovine ephemeral fever in Australia and the world. Curr. Top. Microbiol. Immunol. 2005, 292, 57-80. [CrossRef]

11. Walker, P.J.; Klement, E. Epidemiology and control of bovine ephemeral fever. Vet. Res. 2015, 46, 124. [CrossRef]

12. Mlingo, T.A.M.; Nthangeni, B.M.; Mokoena, N.B. Genome sequence of Bovine Ephemeral fever virus vaccine strain of South African origin. Vet. Med. Sci. 2021, 7, 1611-1615. [CrossRef]

13. Uren, M.F.; Walker, P.J.; Zakrzewski, H.; St George, T.D.; Byrne, K.A. Effective vaccination of cattle using the virion G protein of bovine ephemeral fever virus as an antigen. Vaccine 1994, 12, 845-850. [CrossRef]

14. Hertig, C.; Pye, A.D.; Hyatt, A.D.; Davis, S.S.; McWilliam, S.M.; Heine, H.G.; Walker, P.J.; Boyle, D.B. Vaccinia virus-expressed bovine ephemeral fever virus G but not G(NS) glycoprotein induces neutralizing antibodies and protects against experimental infection. J. Gen. Virol. 1996, 77 Pt 4, 631-640. [CrossRef]

15. Johal, J.; Gresty, K.; Kongsuwan, K.; Walker, P.J. Antigenic characterization of bovine ephemeral fever rhabdovirus G and GNS glycoproteins expressed from recombinant baculoviruses. Arch. Virol. 2008, 153, 1657-1665. [CrossRef]

16. Kongsuwan, K.; Cybinski, D.H.; Cooper, J.; Walker, P.J. Location of neutralizing epitopes on the G protein of bovine ephemeral fever rhabdovirus. J. Gen. Virol. 1998, 79 Pt 11, 2573-2581. [CrossRef]

17. Zheng, F.Y.; Lin, G.Z.; Qiu, C.Q. Expression, purification and antigenic characterization of the Epitope-G1 gene of bovine ephemeral fever virus in Escherichia coli. Wei Sheng Wu Xue Bao 2007, 47, 498-502. [PubMed]

18. Omar, R.; Van Schalkwyk, A.; Carulei, O.; Heath, L.; Douglass, N.; Williamson, A.L. South African bovine ephemeral fever virus glycoprotein sequences are phylogenetically distinct from those from the rest of the world. Arch. Virol. 2020, 165, 1207-1210. [CrossRef] [PubMed]

19. Dhillon, J.; Cowley, J.A.; Wang, Y.; Walker, P.J. RNA polymerase (L) gene and genome terminal sequences of ephemeroviruses bovine ephemeral fever virus and Adelaide River virus indicate a close relationship to vesiculoviruses. Virus Res. 2000, 70, 87-95. [CrossRef]

20. Sanchez-Sampedro, L.; Perdiguero, B.; Mejias-Perez, E.; Garcia-Arriaza, J.; Di Pilato, M.; Esteban, M. The evolution of poxvirus vaccines. Viruses 2015, 7, 1726-1803. [CrossRef] [PubMed]

21. Prow, N.A.; Jimenez Martinez, R.; Hayball, J.D.; Howley, P.M.; Suhrbier, A. Poxvirus-based vector systems and the potential for multi-valent and multi-pathogen vaccines. Expert Rev. Vaccines 2018, 17, 925-934. [CrossRef]

22. Romero, C.H.; Barrett, T.; Kitching, R.P.; Carn, V.M.; Black, D.N. Protection of cattle against rinderpest and lumpy skin disease with a recombinant capripoxvirus expressing the fusion protein gene of rinderpest virus. Vet. Rec. 1994, 135, 152-154. [CrossRef] [PubMed]

23. Teffera, M.; Babiuk, S. Potential of Using Capripoxvirus Vectored Vaccines against Arboviruses in Sheep, Goats, and Cattle. Front. Vet. Sci. 2019, 6, 450. [CrossRef] [PubMed] 
24. Wallace, D.B.; Mather, A.; Kara, P.D.; Naicker, L.; Mokoena, N.B.; Pretorius, A.; Nefefe, T.; Thema, N.; Babiuk, S. Protection of Cattle Elicited Using a Bivalent Lumpy Skin Disease Virus-Vectored Recombinant Rift Valley Fever Vaccine. Front. Vet. Sci. 2020, 7, 256. [CrossRef]

25. Haegeman, A.; De Leeuw, I.; Mostin, L.; Campe, W.V.; Aerts, L.; Venter, E.; Tuppurainen, E.; Saegerman, C.; De Clercq, K. Comparative Evaluation of Lumpy Skin Disease Virus-Based Live Attenuated Vaccines. Vaccines 2021, 9, 473. [CrossRef] [PubMed]

26. Ben-Gera, J.; Klement, E.; Khinich, E.; Stram, Y.; Shpigel, N.Y. Comparison of the efficacy of Neethling lumpy skin disease virus and x10RM65 sheep-pox live attenuated vaccines for the prevention of lumpy skin disease-The results of a randomized controlled field study. Vaccine 2015, 33, 4837-4842. [CrossRef] [PubMed]

27. Klement, E.; Broglia, A.; Antoniou, S.E.; Tsiamadis, V.; Plevraki, E.; Petrovic, T.; Polacek, V.; Debeljak, Z.; Miteva, A.; Alexandrov, T.; et al. Neethling vaccine proved highly effective in controlling lumpy skin disease epidemics in the Balkans. Prev. Vet. Med. 2020, 181, 104595. [CrossRef]

28. Hamdi, J.; Boumart, Z.; Daouam, S.; El Arkam, A.; Bamouh, Z.; Jazouli, M.; Tadlaoui, K.O.; Fihri, O.F.; Gavrilov, B.; El Harrak, M. Development and Evaluation of an Inactivated Lumpy Skin Disease Vaccine for Cattle. Vet. Microbiol. 2020, 245, 108689. [CrossRef]

29. Douglass, N.; Munyanduki, H.; Omar, R.; Gers, S.; Mutowembwa, P.; Heath, L.; Williamson, A.L. Influence of the Viral Superoxide Dismutase (SOD) Homologue on Lumpy Skin Disease Virus (LSDV) Growth, Histopathology and Pathogenicity. Vaccines 2020, 8 , 664. [CrossRef]

30. Munyanduki, H.; Douglass, N.; Offerman, K.; Carulei, O.; Williamson, A.L. Influence of the lumpy skin disease virus (LSDV) superoxide dismutase homologue on host transcriptional activity, apoptosis and histopathology. J. Gen. Virol. 2020, 101, 645-650. [CrossRef]

31. Munyanduki, H.; Omar, R.; Douglass, N.; Williamson, A.L. Removal of bovine viral diarrhea virus (BVDV) from lumpy skin disease virus (LSDV) vaccine stocks by passage on chorioallantoic membranes of fertilized hens' eggs. J. Virol. Methods 2020, 275, 113752. [CrossRef] [PubMed]

32. Reed, L.J.; Muench, H. A simple method of estimating fifty per cent endpoints. Am. J. Epidemiol. 1938, 27, 493-497. [CrossRef]

33. Wyatt, L.S.; Shors, S.T.; Murphy, B.R.; Moss, B. Development of a replication-deficient recombinant vaccinia virus vaccine effective against parainfluenza virus 3 infection in an animal model. Vaccine 1996, 14, 1451-1458. [CrossRef]

34. Kumar, S.; Boyle, D.B. A poxvirus bidirectional promoter element with early/late and late functions. Virology 1990, 179, 151-158. [CrossRef]

35. Chakrabarti, S.; Sisler, J.R.; Moss, B. Compact, synthetic, vaccinia virus early/late promoter for protein expression. Biotechniques 1997, 23, 1094-1097. [CrossRef]

36. Hammond, J.M.; Oke, P.G.; Coupar, B.E. A synthetic vaccinia virus promoter with enhanced early and late activity. J. Virol. Methods 1997, 66, 135-138. [CrossRef]

37. Kara, P.D.; Afonso, C.L.; Wallace, D.B.; Kutish, G.F.; Abolnik, C.; Lu, Z.; Vreede, F.T.; Taljaard, L.C.; Zsak, A.; Viljoen, G.J.; et al. Comparative sequence analysis of the South African vaccine strain and two virulent field isolates of Lumpy skin disease virus. Arch. Virol. 2003, 148, 1335-1356. [CrossRef]

38. Diepen, M.v.; Chapman, R.; Douglass, N.; Whittle, L.; Chineka, N.; Galant, S.; Cotchobos, C.; Suzuki, A.; Williamson, A.-L. Advancements in the Growth and Construction of Recombinant Lumpy Skin Disease Virus (LSDV) for Use as a Vaccine Vector. Vaccines 2021, 9, 1131. [CrossRef]

39. Bellstedt, D.; Human, P.; Rowland, G.; Van der Merwe, K. Acid-treated, naked bacteria as immune carriers for protein antigens. J. Immunol. Methods 1987, 98, 249-255. [CrossRef]

40. Zhang, M.; Ge, J.; Wen, Z.; Chen, W.; Wang, X.; Liu, R.; Bu, Z. Characterization of a recombinant Newcastle disease virus expressing the glycoprotein of bovine ephemeral fever virus. Arch. Virol. 2017, 162, 359-367. [CrossRef] [PubMed]

41. Tulman, E.R.; Afonso, C.L.; Lu, Z.; Zsak, L.; Kutish, G.F.; Rock, D.L. Genome of lumpy skin disease virus. J. Virol. 2001, 75, 7122-7130. [CrossRef]

42. Aziz-Boaron, O.; Gleser, D.; Yadin, H.; Gelman, B.; Kedmi, M.; Galon, N.; Klement, E. The protective effectiveness of an inactivated bovine ephemeral fever virus vaccine. Vet. Microbiol. 2014, 173, 1-8. [CrossRef]

43. Della-Porte, A.J.; Snowdon, W.A. Vaccines against bovine ephemeral fever. Aust. Vet. J. 1977, 53, 50-51. [CrossRef]

44. Inaba, Y.; Kurogi, H.; Sato, K.; Goto, Y.; Omori, T.; Matumoto, M. Formalin-inactivated, aluminum phosphate gel-adsorbed vaccine of bovine ephemeral fever virus. Arch. Gesamte Virusforsch. 1973, 42, 42-53. [CrossRef]

45. Lo, Y.T.; Tulloch, F.; Wu, H.C.; Luke, G.A.; Ryan, M.D.; Chu, C.Y. Expression and immunogenicity of secreted forms of bovine ephemeral fever virus glycoproteins applied to subunit vaccine development. J. Appl. Microbiol. 2021, 131, 1123-1135. [CrossRef] [PubMed]

46. Zheng, W.; Zhao, Z.; Tian, L.; Liu, L.; Xu, T.; Wang, X.; He, H.; Xia, X.; Zheng, Y.; Wei, Y.; et al. Genetically modified rabies virus vector-based bovine ephemeral fever virus vaccine induces protective immune responses against BEFV and RABV in mice. Transbound. Emerg. Dis. 2020, 68, 1353-1362. [CrossRef]

47. Wallace, D.B.; Viljoen, G.J. Immune responses to recombinants of the South African vaccine strain of lumpy skin disease virus generated by using thymidine kinase gene insertion. Vaccine 2005, 23, 3061-3067. [CrossRef] [PubMed] 
48. Cohen, A. Lumpy skin disease virus as a vaccine vector for rift valley fever virus and bovine ephemeral fever virus. In Proceedings of the 4th Congress of the European Society for Veterinary Virology, Edinburgh, Scotland, 24-27 August 1997; pp. 230-231.

49. Zheng, F.Y.; Chen, Q.W.; Li, Z.; Gong, X.W.; Wang, J.D.; Yin, H. Experimental infection with bovine ephemeral fever virus and analysis of its antibody response cattle. Res. Vet. Sci. 2016, 104, 146-151. [CrossRef] [PubMed]

50. Aspden, K.; Passmore, J.A.; Tiedt, F.; Williamson, A.L. Evaluation of lumpy skin disease virus, a capripoxvirus, as a replicationdeficient vaccine vector. J. Gen. Virol. 2003, 84, 1985-1996. [CrossRef] [PubMed]

51. Milovanovic, M.; Dietze, K.; Milicevic, V.; Radojicic, S.; Valcic, M.; Moritz, T.; Hoffmann, B. Humoral immune response to repeated lumpy skin disease virus vaccination and performance of serological tests. BMC Vet. Res. 2019, 15, 80. [CrossRef]

52. Mok, D.Z.L.; Chan, K.R. The Effects of Pre-Existing Antibodies on Live-Attenuated Viral Vaccines. Viruses 2020, 12, 520. [CrossRef] [PubMed] 